\title{
Enablers and Inhibitors of AI-Powered Voice Assistants: A Dual-Factor Approach by Integrating the Status Quo Bias and Technology Acceptance Model
}

\author{
Janarthanan Balakrishnan ${ }^{1} \cdot$ Yogesh K. Dwivedi $^{2,3}$ (D) $\cdot$ Laurie Hughes $^{2} \cdot$ Frederic Boy $^{4}$
}

Accepted: 8 September 2021

(c) The Author(s) 2021

\begin{abstract}
This study investigates the factors that build resistance and attitude towards AI voice assistants (AIVA). A theoretical model is proposed using the dual-factor framework by integrating status quo bias factors (sunk cost, regret avoidance, inertia, perceived value, switching costs, and perceived threat) and Technology Acceptance Model (TAM; perceived ease of use and perceived usefulness) variables. The study model investigates the relationship between the status quo factors and resistance towards adoption of AIVA, and the relationship between TAM factors and attitudes towards AIVA. A sample of four hundred and twenty was analysed using structural equation modeling to investigate the proposed hypotheses. The results indicate an insignificant relationship between inertia and resistance to AIVA. Perceived value was found to have a negative but significant relationship with resistance to AIVA. Further, the study also found that inertia significantly differs across gender (male/female) and age groupings. The study's framework and results are posited as adding value to the extant literature and practice, directly related to status quo bias theory, dual-factor model and TAM.
\end{abstract}

Keywords Voice assistants $\cdot$ Artificial intelligence $\cdot$ Dual-factor model $\cdot$ Status quo bias theory $\cdot$ Resistance to change

\section{Introduction}

Yogesh K. Dwivedi

y.k.dwivedi@swansea.ac.uk

Janarthanan Balakrishnan

reachjanarthanan@gmail.com

Laurie Hughes

d.1.hughes@swansea.ac.uk

Frederic Boy

f.a.boy@swansea.ac.uk

1 Department of Management Studies, National Institute of Technology - Tiruchirappalli, Tiruchirappalli, India

2 Emerging Markets Research Centre (EMaRC), School of Management, Swansea University Bay Campus, Fabian Bay, Swansea SA1 8EN, Wales, UK

3 Department of Management, Symbiosis Institute of Business Management, Pune \& Symbiosis International (Deemed University), Pune, Maharashtra, India

4 iLab, School of Management, Swansea University Bay Campus, Fabian Bay, Swansea SA1 8EN, Wales, UK
The growth of industry 4.0 has greatly emphasized the development of Artificial Intelligence (AI) related infrastructure at different levels of the value chain and business cycles where AI has increasingly contributed to the betterment of human life (Cao et al., 2021; Coombs, 2020; Grover et al., 2020; Sipior, 2020). Minsky (1968, p. v) defines $\mathrm{AI}$ as the "the science of making machines do things that would require intelligence if done by men". The emergence of voice assistants has enabled organisations to develop systems and processes where human interaction with $\mathrm{AI}$ has become the norm (Bawack et al., 2021; Hu et al., 2021). The first voice assistant titled "Shoebox" was introduced by IBM at the Seattle world fair in 1962. Apple has been working on voice assistants since 1990 and has developed a pilot with Macintosh Plain Talk during 1993. Since 2010, voice assistants' use and functions have become ubiquitous across numerous human-system interactions. Various companies have launched voice assistant devices and associated smartphone applications, namely: Siri (Apple), Google Now (Google), Cortana (Microsoft), and Alexa (Amazon). Voice assistants tend to use AI models to integrate and connect 
various customer actions (MIT Technology Review, 2019). Predominantly voice assistant devices use IoT (Internet of Things) technology to connect with consumer interactions (Santos et al., 2016). Though driven by AI algorithms, voice assistants store user conversations and other accepted data to optimize performance outcomes (Dwivedi et al., 2021a; Vimalkumar et al., 2021a). Lately, big data analytics has been used in conjunction with AI technologies to offer new efficiencies and increased capability within a wide spectrum of industries (Duan et al., 2019; Mikalef et al., 2019; Popovič et al., 2018) and user end (Lee, 2017; Pappas et al., 2018).

AI-enabled voice assistants are the most notable and ubiquitous advancement of AI related innovations to emerge during the last decade (Balakrishnan \& Dwivedi, 2021a; Collins et al., 2021; Kumar et al, 2021). From gathering information based on voice queries, to commercial bookings, voice assistants have increased the range of applications for the benefit of users (Balakrishnan \& Dwivedi, 2021b). Despite the growing functionality of AI-enabled voice assistants, the literature has offered scant attention to understand the attitudes toward this evolving technology (Grover et al., 2020). The literature has explored the technical aspects of voice assistants, but seems to have offered very limited empirical research to seeks to more deeply understand user attitudes and resistance within this area. Researchers have argued that consumers traditionally tend to resist interacting with the automated and artificial environment (Dwivedi et al., 2021b; Klumpp, 2018). The report by McKinsey Global Institute, states that users of AI face issues at the personal and regulatory level that directly impact interaction (Chui et al., 2018). Despite users having adequate knowledge of voice assistants and AI, resistance tends to centre around using voice assistants due to perceptions of value, and cost (PWC, 2018).

This study frames its research on the deeper analysis and understanding of the significant personal factors that can lead to user resistance in the use of AI-based Voice Assistants (AIVA) and key drivers that build a positive attitude towards AIVA. Industry analysis from Statista predicts that digital voice assistants' usage is expected to grow to 8.4 billion in 2024 from 3.25 billion in 2019 (Tankovska, 2020). Unlike some AI devices, voice assistants involve a range of users from different age and gender groups (McLean \& Osei-Frimpong, 2019). Despite various AI functions emerging during this decade, the literature has omitted to compare attitude disposition or resistance based on the enhancing and inhibiting factors. Given that voice assistants are recognized as home devices (Seetharaman et al., 2020), it is important to investigate how users across age and gender groups exhibited a positively affect their attitude and resistance towards these devices.

From the above discussion and analysis of the extant literature, this study has identified three gaps, (1) A distinct lack of understanding of the inhibiting factors that can lead to resistance towards AIVA (Chi et al., 2020); (2) There exists a limited comprehension of the key enabling factors that can build a positive attitude towards AIVA (Borges et al., 2021; Chi et al., 2020; Gursoy et al., 2019); (3) Although researchers such as Duan et al. (2019) and Han and Yang (2018) propose that influence towards AI devices can be related to user characteristics recommending further research to investigate the moderating role of age and gender for the relationships associated with AIVA, researchers have yet to empirically investigate the role of gender and age groups in creating resistance and attitude towards AIVA. The gaps above are important both from a theoretical and practical perspective leading to the the following research questions:

RQ1 What are the inhibitors that enhance resistance towards AI voice assistants (AIVA)?

RQ2 What are the enablers that help to form a positive attitude towards AI voice assistants (AIVA)?

RQ3 What are the gender and age groups' role in the relationship between inhibitors - resistance and enablers - attitude?

This study addresses the research question through a conceptual framework designed with the help of three theoretical underpinnings. One reason that constrains users to adopt new information systems, is their resistance to change (Markus, 1983). To understand and address such hindrances theoretically, Kim and Kankanhalli (2009), introduced status quo bias (SQB) theory from an IS perspective. SQB theory explains people's preferences and intention to subscribe to the current status rather than exploring new alternatives. Second, as mentioned above, it is important to understand user attitude towards AIVA. For this purpose, this study employs the Technology Acceptance Model (TAM) (Dwivedi et al., 2019), to investigate the user attitude towards AIVA. Thus the present study integrates SQB theory and TAM within a dual-factor framework (Herzberg et al., 1959) to address the practical and theoretical gaps in understanding the attitude and resistance towards AI-related devices. The Dual-factor model incorporates the inhibitors and enablers to understand the decision roles of individuals.

Via the analysis of the research questions, this study contributes to the literature from a theoretical and practical context; (1) By employing the dual-factor model and integrating SQB theory and TAM, thereby extending the scope and application of the model within an IS research viewpoint; (2) By employing SQB variables as inhibitors, the model results will increase the scope of SQB theory from the AI perspective; (3) This research explores the inherent relationship between resistance and attitude, filling a gap in the literature relating to user attitude theories and resistance; (4) Importantly, RQ3 unveils the role of gender and 
age in the relationships proposed within the dual-factor model. The results will add new theoretical implications for the use of SBQ theory and TAM; (5) Finally, the application of theories (such as cognitive psychology theory and rational choice theory are posited as adding further knowledge within this important area of theliterature. Besides the theoretical implications, the results of the RQ's can provide valuable insights for practitioners and the results will guide marketers in addressing the significant inhibitors in reducing resistance to adopting AIVA.

The paper's remaining structure is organized as follows; first, the theoretical background of the dual-factor model, SQB theory, TAM and the model hypotheses are discussed. Second, the methodology, analysis, and results are presented. Finally, the results are discussed in conjunction with the theoretical and practical implications stemming from this research.

\section{Theoretical Background}

\subsection{Adoption of AIVA}

Among the growing frontline of AI-based technologies, voice assistants are becoming ubiquitous (Kendall et al., 2020). AIVA has made a significant impact to end user engagement (McLean \& Osei-Frimpong, 2019; Sung et al., 2021) and customer service domain interaction (Kumar et al., 2016). AIVA are capable of learning from user interaction and provide an optimized experience for end users. Adoption of AI-related technologies has been investigated within a number of different contexts such as; robots in tourism (Tussyadiah, 2020), self-driving intelligent vehicles (Shariff et al., 2017), augmented reality and virtual reality adoption in store-based retailing (Han et al., 2018; Zhang et al., 2021), healthcare (Shareef et al., 2021) and automated retail stores (Pillai et al., 2020). Similar to other AI-related technology, AIVA has extended various applications to the end user such as; home usage, bookings, conversational commerce, service enquiries, etc. Thus the growing applications in AIVA have provided a case for its adoption among the end users. Researchers have used different terminologies to describe AIVA such as: intelligent personal assistants (Han \& Yang, 2018) and digital voice assistants (Fernandes $\&$ Oliveira, 2021). However, generally these terminologies describe AIVA in the context of the product rather than the technology. A relatively limited number of studies have attempted to investigate AIVA user adoption behaviour (Fernandes \& Oliveira, 2021; Han \& Yang, 2018). Han and Yang (2018) found that parasocial relationships and satisfaction can positively influence the adoption of intelligent voice assistants. Fernandes and Oliveira (2021) found that relationship elements (trust and rapport) contribute more to the acceptance and adoption of digital voice assistants. McLean and Osei-Frimpong (2019) found that social factors can enhance the usage of voice assistants. While considerable knowledge is available to understand the adoption of voice assistants, but there is no study which has aimed to present alternative perspectives. Studies have asserted the importance of investigating the factors that exhibit resistance behaviours amongst IS users (Kim \& Kankanhalli, 2009). By investigating the factors underlying resistance, researchers can potentially engender successful adoption of IS and enable further technology innovation (Roy et al., 2018).

\subsection{Dual Factor Theory}

Herzberg et al.'s (1959) dual-factor theory states that humans have different sets of needs, leading to a positive or negative outcome, resulting in satisfaction or dissatisfaction. IS research references this phenomenon in the context of enablers (leading to adoption) and inhibitors (leading to resistance). Herzberg et al. (1959) investigated this phenomenon in the context of job satisfaction, later the model was adopted within different contexts such as; education (Suldo et al., 2016) and consumer behaviour (Park et al., 2018). Limited studies have applied the concept of dual-factor theory within an IS environment. Notably, Lin et al. (2015) utilised constraint and dedication factors that build loyalty towards IT products. The research by Cenfetelli (2004) applied the dual-factor theory to IS to explain the inhibitors and enablers relating to adoption. The Cenfetelli study developed a proposition matrix where the underlying enablers and inhibitors are IS usage and user perception functions. In the IS context, various studies have identified different enablers and inhibitors. This study builds on the research from Herzberg et al. (1959) and Cenfetelli (2004) by positioning the variables of TAM as the enablers (perceived ease of use and perceived usefulness) and SQB theory dimensions as inhibitors to understand the attitude towards AIVA and resistance towards adoption of AIVA respectively.

\subsection{Status Quo Bias Theory (Inhibitors)}

SQB theory proposes that people tend to continue their present situation although alternatives or potential changes are available (Samuelson \& Zeckhauser, 1988). SBQ is derived from the tenets of psychological theories and applied across various disciplines within decision-making. The theory is used extensively in the areas of economic choices (Masatlioglu \& Ok, 2005), knowledge management systems (Chiu et al., 2021; Li et al., 2016), healthcare systems (Hsieh, 2015; Zhang et al., 2017), entrepreneurial decisions (Burmeister \& Schade, 2007), conservatism and value (Nebel, 2015), as well as clinical researches (Karl et al., 2019). However, in recent years, SQB theory has received renewed 
attention from IS researchersdue to the radical development of new technologies and users differentiated approach to adoption.

Samuelson and Zeckhauser (1988) describe three categories of constructs that can comprehensively define SQB, namely, psychological commitment, cognitive misperception, and rational decision making. The first construct; Psychological commitment, refers to the inner self-commitment that the user sustains during resistance in adopting a new system. Psychological commitment with existing technology generally arises due to two reasons; (i) based on the resources or time already invested in the existing system, (switching over to the new system investment may result in a sunk cost); (ii) a pre-measure to avoid regret during the process of adopting a new system. The Zeckhauser (1988) study highlights that sunk cost and regret avoidance can instill a psychological commitment to building resistance to adopt a new system. The second construct, misperception, refers to a comprehension distorted by our existing value or belief system. Cognitive misperception allows users to rationally evaluate the benefits and costs that serve as a base to accept or resist a change. This construct: (i) operationalized when users exhibit safety and enjoy retaining the existing state (known as inertia), and (ii) when users perceive greater benefits than costs (perceived value, they tend to reduce levels of resistance. The final construct, rational decision-making, explains that users cognitively process the benefits and values derived, by switching over to a new system. When the user sees more switching costs or any underlying threat associated with the new technology, they tend to restrain from switching over to a new system (Lee \& Joshi, 2017). Rational decision making includes two important factors (i) transition costs, besides the costs already invested (a sunk cost) that the user calculates as a cost required to invest more to adapt to a new system, (ii) the perceived uncertainty that may exist from the new system. The inhibitors, namely, sunk costs, regret avoidance, transition costs, and uncertainty, tend to build resistance toward adoption. While the abovementioned factors can play an inhibitor role within SQB, perceived value tends to act as an enabler within the model. This is mainly due to previous studies that have supported that perceived value exhibits a negative relationship with resistance towards IS (Kim \& Kankanhalli, 2009). The SQB comprises of five inhibitors and one enabler.

\subsection{TAM (Enabler)}

Davis (1989) proposed and validated TAM, (an accomplished IS research model). and explains two major factors underlying the motivation to accept a technology: perceived usefulness and ease of use. Davis (1989) posits that these two factors enable a user to form a positive disposition to accept technology. Perceived ease of use can be explained as the degree to which the users feel that the technology will reduce their effort thereby enabling ease of use; whereas perceived usefulness can be explained as the degree to which the users feel the technology will enhance their performance (Davis, 1989; Davis et al., 1989). The constructs, perceived usefulness and perceived ease of use are extensively used in various contexts and technology-oriented research to understand its relation with technology acceptance (Davis, 1989; Davis et al., 1989; Sharma, 2019), attitude towards technology (Dwivedi et al., 2019; Elias et al., 2012), technology trust (Alalwan et al., 2018; Gefen et al., 2003), and technology continuation intention (Tam et al., 2020). After TAM, Venkatesh and Davis (2000) proposed TAM2 (Extension of TAM) by introducing five new predictors (subjective norm, image, job relevance, output quality, result demonstrability) to perceived usefulness. The research uses the important common constructs present in both TAM and TAM2 (perceived ease of use and perceived usefulness) to bring a theoretical view. Overall, this research posits that no research has attempted to integrate TAM as an enabler for Dual Factor Theory. This research employs perceived usefulness and ease of use as enablers in the Dual Factor Theory to understand its relationship with AI-related voice assistants' attitude.

\section{Model and Hypotheses}

Assimilating from the preceding theoretical discussions, we propose that the six constructs derived from the tenets of SBQ theory that can describe the resistance that users exhibit to adopting AI-powered voice assistants. In parallel, we also propose that TAM's two profounding constructs (perceived usefulness and perceived ease of use) can instill a positive attitude among users. The study model integrates the SBQ theory and TAM within a dual-factor framework to investigate the relationship between the resistance to adoption of AIVA and attitude towards AIVA. This study's hypothetical model is illustrated in Fig. 1.

\subsection{Psychological commitment to resistance}

Commitment refers to an implicit or explicit pledge of continuous relationship (Rauyruen \& Miller, 2007). In marketing terms, Moorman et al., (1992, p. 316) explain commitment as a customer's desire to uphold a valued relationship to warrant maximum efforts at maintaining it. Further, psychological commitment refers to a deep affective level to which a user or customer upholds a change. Many studies have highlighted that psychological commitment can instill additional resistance to any change, but mostly within the organizational context (Lines, 2004; Morin et al., 2016). Limited elements of the literature have investigated 
Fig. 1 Proposed model of the study (Source: Adapted from Samuelson \& Zeckhauser, 1988; Davis, 1989; Kim \& Kankanhalli, 2009)
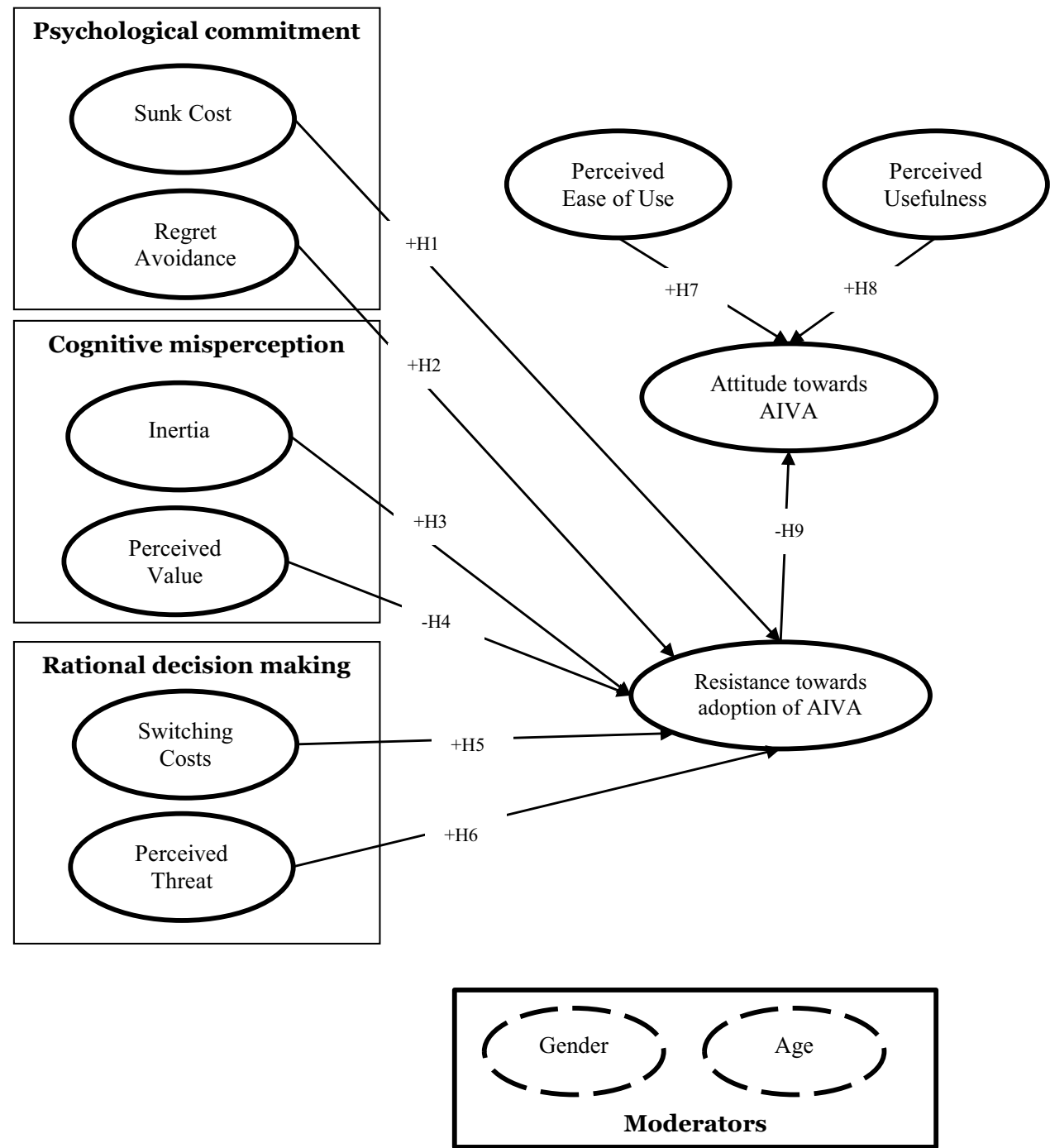

the role of psychological commitment and its relationship with resistance towards any IS technology (Kim \& Kankanhalli, 2009; Lee \& Joshi, 2017). Psychological commitment is similar to a psychological contract where users develop a cognitive agreement that can direct users to forego any alternative for change. Psychological commitment construct comprises of two dimensions, namely, sunk cost and regret avoidance.

Chung and Cheng (2018) highlighted cognitive dissonance as an intervening variable between sunk cost and resistance to change. Given that cognitive dissonance is built from cognitive psychology frameworks (Brehm \& Cohen, 1962), users can be naturally afraid of a dissonant cognitive state to accept any change. By building our arguments through the tenets of cognitive psychological frameworks, we propose that sunk costs associated with existing technology will positively build users' resistance towards AIVA. The following hypothesis is proposed based on the above discussion.
Hypothesis 1 Sunk cost will have a positive relationship with resistance towards adoption of AIVA.

As stated in the above hypothesis, cognitive dissonance plays a major role in instilling resistance to change (Marikyan et al., 2020). Brehm and Wicklund (1970) position dissonance as a form of regret, that an individual constantly attempts to reduce. Within the recent technology-related literature, Marikyan et al. (2020) found that dissonance can build regret towards technology. Moreover, previous studies have supported that regret avoidance is a major variable that can increase resistance to adopt a change (Hsieh \& Lin, 2018). Given that cognitive psychology theories state that individuals tend to reduce the dissonance factor caused due to any decision, users can resist using a voice assistant to avoid any future regrets caused due to many factors. So assimilating from the above theoretical and rational support, we propose the following hypothesis. 
Hypothesis 2 Regret avoidance will have a positive relationship with resistance towards adoption of AIVA.

\subsection{Cognitive Misperception with Resistance}

Cognitive misperception refers to a conscious error derived from our past experiences. Pronin (2007) explains that perceptions and misperceptions are judgments arising out of cognitive biases. Cognitive misperception explains that past and present experiences can engender resistance to adopt a new change, whilst at the same time, a significant value aspect associated with the change, can lead to a reduction in resistance. These two states of cognitive misperception are represented as inertia and perceived value. Inertia is a conscious judgment developed due to the comforts that an individual feels from an existing situation. Such inertia is manifested from organizational routines down to individual behaviors and attitudes (Besson \& Rowe, 2012; Mikalef et al., 2020). Samuelson and Zeckhauser (1988) highlight that individuals tend to develop stress or cognitive discomfort to change. The same can apply to IS technology adoption when users may feel uncomfortable with the existing technology and thereby resist change. Del Val and Fuentes (2003) stated that inertia builds resistance following two stages: distorted perceptions and further strengthening due to deep routed values. Li et al. (2016) argued that inertia could be comprehended at cognitive, affective, and conative levels. However, this research attempts to investigate inertia at the cognitive level. Building from the rational and theoretical arguments stated above, we propose that inertia can significantly influence users in resisting the adoption of AIVA.

Hypothesis 3 Inertia will have a positive relationship with resistance towards adoption of AIVA.

IS users tend to leverage the costs and benefits when adopting new technology. Users may feel that the existing system offers significant value, and consequently may resist accepting any change (Kim \& Kankanhalli, 2009). Skepticism is one of the major variables that builds resistance to change (Owen-Smith, 2001). However, when an individual perceives a higher value in an alternative, skepticism for the change tends to reduce (Koller et al., 2011). Pearson et al. (2012) stated that users perceived value toward technology could instill strong loyalty. When an individual forms a highvalue perception towards action, the same may reduce the prevailing cognitive distortion, subsequently reducing the impact of resistance. As mentioned above, though perceived value acts as an integral dimension of SQB, the context of its relationship with resistance towards adoption of AIVA, term it as an enabler. Based on the theoretical and rational arguments stated above, the following hypothesis is proposed:
Hypothesis 4 Perceived value will have a negative relationship with resistance towards adoption of AIVA.

\subsection{Rational Decision Making and Resistance}

Rational Choice Theory (RCT) is an economic approach that explains the human decision making process among the given alternatives (Bulgurcu et al., 2010). RCT argues that every individual decision is bounded with rationality in terms of cost and benefit perceptions. Although various outcomes are possible from a state of choice, individuals tend to contemplate likely outcomes based on their rational judgments (Paternoster \& Pogarsky, 2009). Thus a rational choice can both result in adoption and resistance towards evaluating a choice. The RCT states that humans evaluate their alternatives based on both functional and psychological benefits and cost before arriving at a rational decision (Bulgurcu et al., 2010). Given the dynamic advancement in technology in recent times, adopting new technology does involve transition costs (Dang et al., 2017). From the above discussion, it is evident that IS users can resist adopting a technology after evaluating the cost and benefit involved in the transition. SQB theory states that rational decision-making consists of two dimensions: switching cost (transition cost) and perceived threat (based on uncertainty).

Switching costs is one of the main concerns prohibiting users from transitioning to a new alternative (Kapoor et al., 2018). In their review, Whitten and Wakefield (2006) emphasized that switching costs in IT involve both functional and psychological costs associated with the technology. Functional costs refer to the transaction elements that are associated with the changewhilst psychological costs entail the time and effort associated with the implementation of change. Loss aversion is a psychological principle that users rationally adopt during any change process ( $\mathrm{Li}$ et al., 2016). The same principle can apply in this context, where users can resist adopting AIVA because of the perceived loss that occurs due to switching costs (For example: A user who attempts to adopt AIVA may be afraid of the losses due to the high investment of time and money in the new technology). Foregoing the psychological bonding present with the existing technology is a loss for the users, when they attempt to switchover to a new technology (Burnham et al., 2003). Since this technology involves both functional and psychological investment to adopt, there is a greater possibility that users can resist the technology when they evaluate a higher cost associated with switching. From the above discussion, the following hypothesis is proposed.

Hypothesis 5 Switching costs will have a negative relationship with resistance towards adoption of AIVA.

Threat and security is an inevitable factor that grows alongside technology (Yang \& Lee, 2016). Users of IS are 
threatened when their existing perception of technology is challenged by any likelihood of potential lossand lead to resistance towards new technology (Bhattacherjee \& Hikmet, 2007). Clinical psychological theories relate perceived threat to humans uncertainty (Tanovic et al., 2018). The same can apply in the context of technology; when users are uncertain about the technology or functions, it can lead to a perceived threat. Given the complex algorithms and anthropomorphic features persistent in AI devices, users of AIVA can feel uncertain about the technology and whether the threat factor grows (Vimalkumar et al., 2021b). Hence, the threat perceived in the AIVA may lead to resistance towards these devices. The following hypothesis is proposed based on the arguments mentioned above.

Hypothesis 6 Perceived threat will have a negative relationship with resistance towards adoption of AIVA.

\subsection{Perceived Ease of Use, Usefulness, and Attitude}

TAM positioned perceived ease of use and perceived usefulness as individual beliefs that form a positive or negative disposition (Davis, 1989; Davis et al., 1989). By grounding the arguments from the theory of reasoned action (TRA), TAM proposed two important constructs, namely, perceived usefulness (PU) and perceived ease of use (PEU), which are considered to be technology-oriented beliefs that influence attitude and behavioural intention.

PEU is the extent to which users believe a technology usage will be free from effort.. Recent literature has supported that AI devices can reduce users efforts (Hengstler et al., 2016)and that PEU can instill a positive attitude among users (Dwivedi et al., 2019; Kim \& Garrison, 2009). However, little research is available to understand how the same applies to voice assistants. Based on the above discussion, the following hypothesis is proposed.

Hypothesis 7 Perceived Ease of Use will have a positive relationship with the attitude towards AIVA.

PU is another important variable within TAM, enabling users to formulate their belief towards the technology based on performance. Previous studies have identified PU as the primary variable, which builds a positive disposition towards technology (Kim \& Garrison, 2009). AI devices are naturally competent within a multitasking context (Lemley et al., 2017). AI devices are more optimised after every update, which indicates that the performance will be progressive as time passes. However, there is little evidence available to understand how users associate PU with AIVA. Based on the discussion above, we propose the following hypothesis.

Hypothesis 8 Perceived Usefulness will have a positive relationship with the attitude towards AIVA.
Zaltman and Duncan (1977) defined resistance to change as 'any conduct that serves to maintain the status quo in the face of pressure to alter the status quo' (p. 63). Previous studies have supported that resistance to change can affect technology usage intention (Bhattacherjee \& Hikmet, 2007). However, to the best of our knowledge, no study has directly estimated the relationship between resistance and attitude. Attitude is a positive or negative disposition based on the underlying nature of the influencing factors. Resistance to change influences the technology usage intention (Bhattacherjee \& Hikmet, 2007) and the positive relationship between technology usage intention and attitude. We assume that resistance to AIVAwill negatively impact attitude formation. Hence, the following hypothesis is proposed.

Hypothesis 9 Resistance towards adoption of AIVA will have a negative relationship with attitude towards AIVA.

\subsection{Role of Gender and Age Groups}

Cai et al. (2017), in their review of 50 articles, found that the belief and attitude towards technology significantly differed across the male and female population. To our knowledge no specific study exists that has contrasted the gender differences in terms of resistance towards technology and attitude formation based on PEU and PU. Steinberg and Monahan (2007) found variation in the levels of psychological resistance towards peer influence between males and females. Building on the studies from Cai et al. (2017) and Steinberg and Monahan (2007), this study assumes that the hypothesis from 1 to 9 will demonstrate measurable gender variance. Thus we propose the following hypothesis.

Hypothesis 10 There will be a significant difference in the path estimates proposed from hypothesis 1 to 9 within gender groups.

Morris and Venkatesh (2000) found that increases in age can negatively moderate attitudes to technology adoption. Similarly, Chaouali and Souiden (2019) found a relationship between psychological/functional barriers and resistance to interacting with online banking and that resistance can significantly differ across age groups. However, the extant literature has failed to compare age based demographics to understand the difference in adoption of technology. From the above discussion and the cues from $\mathrm{H} 1$ to $\mathrm{H} 9$, the following hypothesis is proposed.

Hypothesis 11 There will be a significant difference in the path estimates proposed from hypothesis 1 to 9 for variances within age groups. 
Table 1 Socio-demographic characteristics of the sample

\begin{tabular}{|c|c|c|c|c|}
\hline & Variables & Characteristics & Count & $\%$ \\
\hline \multirow[t]{2}{*}{$\mathrm{CE}$} & Gender & Male & 225 & 53.57 \\
\hline & & Female & 195 & 46.43 \\
\hline \multirow[t]{2}{*}{$\mathrm{CE}$} & Age group & Young (19 to 28 years) & 232 & 55.24 \\
\hline & & Old (29 to 55 years) & 188 & 44.76 \\
\hline \multirow[t]{3}{*}{$\mathrm{CE}$} & Education Qualification & Graduate & 112 & 26.67 \\
\hline & & Post Graduate & 117 & 27.86 \\
\hline & & $\mathrm{PhD}$ & 191 & 45.48 \\
\hline \multirow[t]{3}{*}{$\mathrm{CE}$} & Occupation & Students & 126 & 30.00 \\
\hline & & Working professional & 238 & 56.67 \\
\hline & & Business & 56 & 13.33 \\
\hline \multirow[t]{2}{*}{$\mathrm{CE}$} & Are you aware of Artificial Intelligence and its functions? & Yes & 420 & 100.00 \\
\hline & & No & 0 & 00.00 \\
\hline \multirow[t]{2}{*}{$\mathrm{CE}$} & Are you aware of Voice Assistants? & Yes & 420 & 100.00 \\
\hline & & No & 0 & 00.00 \\
\hline \multirow[t]{6}{*}{$\mathrm{OE}$} & Which is the most important aspect you like in AI voice assistants? & Assistance & 48 & 11.43 \\
\hline & & Control home devices & 36 & 8.57 \\
\hline & & Functions/features & 56 & 13.33 \\
\hline & & Performance & 67 & 15.95 \\
\hline & & Personalised experience & 126 & 30.00 \\
\hline & & Recommendation system & 87 & 20.71 \\
\hline \multirow[t]{6}{*}{$\mathrm{OE}$} & Which is the most important aspect that causes you to & High price & 88 & 20.95 \\
\hline & & Lack of performance & 26 & 06.19 \\
\hline & & No added value & 56 & 13.33 \\
\hline & & No transparency & 62 & 14.76 \\
\hline & & Present usage & 28 & 06.67 \\
\hline & & Privacy concerns & 160 & 38.10 \\
\hline
\end{tabular}

$C E$ Close ended questions; $O E$ open-ended questions

\section{Methodology}

\subsection{Research Design, Procedure, and Participants}

The present research employs a cross-sectional research design. The data was collected from 420 participants comprising of working professionals and students from a diverse background. The detailed socio-demographic information is given in Table 1 . The data was collected directly from participants that attended six AI-related techno-conferences conducted in India. The conferences entailed a theme directly related to AI systems and innovation, including sessions on voice assistants and future growth in this area. The researchers approached potential participants to ensure that the sample possessed adequate knowledge relating to $\mathrm{AI}$ empowerment and emergence of voice assistants. The conferences totalled approximately 1300 attendees, of which an initial 925 were approached to participate in the study, identified through non-probabilistic sampling. Initially, a qualitative screening consisting of the following two questions were asked to arrive at a representative sample: 1. Do you have adequate knowledge on AI and voice assistants (yes/no); 2. Despite your knowledge on the extensive functions prevalent in voice assistants, are you still resistant to adopting voice assistants (yes/no)? A total of 438 participants answered yes for both, 406 participants answered no for at least one question, and finally, 81 participants answered no for both questions. The 438 participants were used as the study sample as they had confirmed knowledge of AIVA, and claimed to be resistant to using this technology. This number was processed via an operationalised instrument based on the interviews of 438 samples and arrived at 420 usable samples. According to $\mathrm{G}^{*}$ Power (statistical power analysis; Faul et al., 2009), we found that with expecting a power of 0.95 , and effect size of 0.15 , a minimum of $178 \mathrm{~s}$ were required for the study. Thus the collected sample is determined adequate. The data collection took place over two months; we assessed nonresponse bias by comparing the responses collected during the early stages with responses collected at later stages (Hsieh, 2015). We found no significant difference in data when comparing the scale means. 


\subsection{Instrument and Measures}

The survey instrument consisted of four parts. The first part of the questionnaire consisted of two categorical questions; (1) Are you aware of the functions of AI? (Yes/No), and (2) Are you aware of voice assistants? (Yes/No). The second part of the instrument measured the study constructs. The scale measurements are derived from the previous studies (Bhattacherjee \& Hikmet, 2007; Hsieh, 2015; Hsu \& Lin, 2008; Kim \& Kankanhalli, 2009; Polites \& Karahanna, 2012; Tsiros \& Mittal, 2000). The constructs related to status quo theory (sunk cost, regret avoidance, inertia, perceived value, switching cost, and perceived threat) are derived from previous studies (Polites \& Karahanna, 2012; Tsiros \& Mittal, 2000; Bhattacherjee \& Hikmet, 2007; Kim $\&$ Kankanhalli, 2009; Hsieh, 2016). The constructs, perceived usefulness, perceived use of use, attitude towards AIVA were derived from Hsu and Lin (2008), and resistance towards AIVA from Bhattacherjee and Hikmet (2007). A seven-point scale was used (7-Very Strongly Agree to 1-Very Strongly Disagree). The third part of the instrument consisted of two opinion based open-ended questions; (1) Which is the most important aspect you like in AI voice assistants (specific one reason)?, (2) Which is the most important aspect that resists you from using voice assistant (specify one reason)? The fourth part of the questionnaire included the socio-demographic information such as; gender, age group, educational qualification, and occupation measured as a categorical variable. Appendix 1 provides more information regarding the measurement scales of the construct.

\subsection{Analysis}

To investigate the proposed model, we employed a two-step structural modelling approach. First, the confirmatory factor analysis (measurement model) is performed to confirm whether the constructs individually and collectively conform with content, convergent, and discriminant validity requirements. Alongside the measurement model, the common method bias test is conducted to confirm the data is free from bias. Second, we tested the proposed hypothesis using the structural equation modelling technique using IBM SPSS AMOS version 26. The model was estimated through the maximum likelihood model to evaluate the path estimates. The multi-group analysis method was used to understand the moderation effect within gender (male/female) and age group (young/old). The variable gender was coded as male and female. To operationalize the variable age, we divided the sample into two groups; young and old. In alignment with the research by Plecher (2020) which stated that the Indian median age as of 2020 can be estimated to be 28.4 years, we divided the age group below 28 years as young and above 28 years as an older sample. A similar methodology is followed in the previous studies (Khan et al., 2020). Prior to estimating the relationships in multi-group analysis, multigroup CFA was first performed to verify the undimensionality and convergent validity of the constructs (Anderson \& Gerbing, 1988).

\section{Results}

\subsection{Respondents' Demographic Characteristics}

The sample consisted of $53.57 \%$ male and $46.43 \%$ female participants, which confirmed that the sample offered largely representative gender distribution. The age group is also diversified among young (55.24\%) and old (44.76\%). Importantly, the screening questions indicated that $100 \%$ of the sample expressed awareness about AI technology and voice assistants, emphasising the sample's representativeness. The fourth part of the questionnaire consisted of two questions: open-ended qualitative questions and the participants' likingness and resistance towards AIVA. The results indicated that personalized experience (30\%) and recommendation system $(20.71 \%)$ are important factors that enhance preference for AIVA. In the case of resistance, privacy concerns (38.10\%) and high prices (20.95\%) are important factors that accelerate resistance towards AIVA from the respondents' perspective. The visual representation of the factors are shown in Appendix 2.

\subsection{CFA and CMB}

The Cronbach's alpha reliability value of the constructs was more than 0.75 , which confirms that the scale is internally consistent (Portney \& Watkins, 2000). Table 2 presents results about CFA. It can be seen that the values of the factor loadings to be above 0.70 ; this confirms the content validity requirements (Nunnally, 1978). Table 2 also shows the average variance extracted (AVE) values above 0.50 , which confirms the threshold requirements for convergent validity (Fornell \& Larcker, 1981).

Table 3 shows the results of inter-correlation values and square root of AVE ( $\sqrt{ }$ AVE) values. The $\sqrt{ }$ AVE values for the respective constructs are above their corresponding inter-correlation values, confirming the requirement for discriminant validity (Fornell \& Larcker, 1981). All validity requirements met the thresholds proposed by Bagozzi et al. (1991) and Fornell and Larcker (1981). The fit indices of measurement model are as follows; $\left(\chi^{2} / \mathrm{df}=2.852\right.$; $\mathrm{NFI}=0.933 ; \mathrm{CFI}=0.955 ; \mathrm{RMSEA}=0.066$ ). According to the recommendations provided in previous research (Byrne, 2010; Hair et al., 2012; Kline, 1998), it was observed that the indices reflected an excellent fit for the measurement model. Further to CFA analysis, common method bias (Podsakoff et al., 2003) is tested using the common latent factor (CLF) 
Table 2 Results of Measurement Model (CFA)

\begin{tabular}{|c|c|c|c|c|c|c|}
\hline Construct & Items & Mean & SD & Factor loadings & $\begin{array}{l}\text { Cronbach's } \\
\text { Alpha }\end{array}$ & AVE \\
\hline \multirow[t]{2}{*}{ Sunk cost } & SC1 & 3.2714 & 1.78234 & $0.905 * * *$ & 0.868 & 0.769 \\
\hline & $\mathrm{SC} 2$ & 3.3571 & 1.76307 & $0.848 * * *$ & & \\
\hline \multirow[t]{2}{*}{ Regret avoidance } & RA1 & 3.3571 & 1.79394 & $0.945^{* * *}$ & 0.920 & 0.854 \\
\hline & RA2 & 3.4000 & 1.71808 & $0.903 * * *$ & & \\
\hline \multirow[t]{4}{*}{ Inertia } & In1 & 3.4524 & 1.80165 & $0.818 * * *$ & 0.935 & 0.795 \\
\hline & $\operatorname{In} 2$ & 3.3548 & 1.69242 & $0.847 * * *$ & & \\
\hline & In3 & 3.3310 & 1.70846 & $0.970 * * *$ & & \\
\hline & In 4 & 3.1929 & 1.48772 & $0.923 * * *$ & & \\
\hline \multirow[t]{3}{*}{ Perceived value } & PV1 & 5.1048 & 1.79191 & $0.956 * * *$ & 0.967 & 0.908 \\
\hline & PV2 & 5.0714 & 1.81604 & $0.949 * * *$ & & \\
\hline & PV3 & 5.0690 & 1.76346 & $0.953 * * *$ & & \\
\hline \multirow[t]{3}{*}{ Switching costs } & SW1 & 3.2833 & 1.95735 & $0.876 * * *$ & 0.881 & 0.721 \\
\hline & SW2 & 3.4357 & 1.96464 & $0.805^{* * *}$ & & \\
\hline & SW3 & 3.3357 & 1.92066 & $0.864 * * *$ & & \\
\hline \multirow[t]{3}{*}{ Perceived threat } & PT1 & 3.4786 & 1.95218 & $0.830 * * *$ & 0.852 & 0.856 \\
\hline & PT2 & 3.4452 & 1.93803 & $0.780 * * *$ & & \\
\hline & PT3 & 3.4405 & 1.95505 & $0.836^{* * * *}$ & & \\
\hline \multirow[t]{3}{*}{ Perceived ease of use } & PEU1 & 4.8857 & 1.64114 & $0.936 * * *$ & 0.958 & 0.885 \\
\hline & PEU2 & 4.8976 & 1.68710 & $0.942 * * *$ & & \\
\hline & PEU3 & 4.9905 & 1.72996 & $0.945 * * *$ & & \\
\hline \multirow[t]{4}{*}{ Perceived usefulness } & PU1 & 4.4905 & 1.86473 & $0.938 * * *$ & 0.965 & 0.966 \\
\hline & PU2 & 4.5000 & 1.82988 & $0.929 * * *$ & & \\
\hline & PU3 & 4.6048 & 1.86565 & $0.969 * * *$ & & \\
\hline & PU4 & 4.3857 & 1.72412 & $0.905 * * *$ & & \\
\hline \multirow[t]{3}{*}{ Attitude towards AIVA } & Att1 & 4.5357 & 1.63090 & $0.939 * * *$ & 0.949 & 0.868 \\
\hline & Att2 & 4.4619 & 1.60577 & $0.940 * * *$ & & \\
\hline & Att3 & 4.6833 & 1.82327 & $0.916 * * *$ & & \\
\hline \multirow{4}{*}{$\begin{array}{l}\text { Resistance towards adop- } \\
\text { tion of AIVA }\end{array}$} & Res1 & 3.8738 & 1.90359 & $0.934 * * *$ & 0.963 & 0.871 \\
\hline & Res2 & 3.8571 & 1.91678 & $0.953 * * *$ & & \\
\hline & Res3 & 3.7429 & 1.78580 & $0.960 * * *$ & & \\
\hline & Res4 & 3.7857 & 1.68718 & $0.885 * * *$ & & \\
\hline
\end{tabular}

CFA Fit indices: $\chi 2 / \mathrm{df}=2.85 ; \mathrm{GFI}=0.912, \mathrm{CFI}=0.955,($ Good fit $>0.9) ; \mathrm{RMSEA}=0.066 \quad(\mathrm{Good}$ fit $<0.06)$; *** $\mathrm{p}<0.001$ method. The standardized estimates of the CLF model are compared with a non-CLF model.

to check for any difference less than 0.05. It was found that the difference between the two models ranges from 0.008 to 0.042 . The results therefore, satisfy the threshold requirement of the CLF method that the data is free from common method bias (MacKenzie \& Podsakoff, 2012).

\subsection{Measurement Invariance Analysis}

A Multigroup measurement invariance test was conducted to check the Chi-square across the configural, scalar, and metric invariance models. First, the free estimate unconstrained model was compared with constrained group model (Steenkamp \& Baumgartner, 1998). Secondly, the constrained group model was compared with the constrained estimated model (Bollen, 1989). Finally, the constrained estimated model was compared with the constrained estimate and mean intercept model. In all the models the change in Chi-Square is found to be insignificant which supported the measurement invariance between gender and age groups. This test also allows multigroup analysis to be performed in order to analyse the relationship difference across the groups. Table 4 shows detailed results of measurement invariance analysis.

\subsection{Structural Equation Modelling Results}

Table 5 shows the results of the hypotheses. The standardized estimates of the paths were considered to interpret the effect size of the hypotheses. It was found that except for hypothesis 
Table 3 Results of Intercorrelation and $\sqrt{ }$ AVE

\begin{tabular}{llrrrrrrrrrr}
\hline & CR & 1 & 2 & 3 & 4 & 5 & 6 & 7 & 8 & 9 & 10 \\
\hline 1. EOU & 0.959 & $\mathbf{0 . 9 4 1}$ & & & & & & & & & \\
2. SC & 0.869 & -0.005 & $\mathbf{0 . 8 7 7}$ & & & & & & & & \\
3. RES & 0.964 & 0.011 & 0.715 & $\mathbf{0 . 9 3 3}$ & & & & & & & \\
4. RA & 0.921 & 0.027 & 0.819 & 0.639 & $\mathbf{0 . 9 2 4}$ & & & & & & \\
5. IN & 0.939 & 0.020 & 0.813 & 0.616 & 0.797 & $\mathbf{0 . 8 9 2}$ & & & & & \\
6. SWC & 0.885 & -0.058 & 0.824 & 0.698 & 0.800 & 0.755 & $\mathbf{0 . 8 4 9}$ & & & & \\
7. PT & 0.856 & -0.014 & 0.802 & 0.729 & 0.795 & 0.766 & 0.753 & $\mathbf{0 . 8 1 6}$ & & & \\
8. PV & 0.967 & 0.238 & -0.673 & -0.575 & -0.586 & -0.565 & -0.579 & -0.626 & $\mathbf{0 . 9 5 3}$ & & \\
9. ATT & 0.952 & 0.376 & -0.318 & -0.270 & -0.206 & -0.251 & -0.176 & -0.284 & 0.575 & $\mathbf{0 . 9 3 2}$ & \\
10. PU & 0.966 & 0.457 & -0.175 & -0.176 & -0.173 & -0.197 & -0.213 & -0.224 & 0.274 & 0.359 & $\mathbf{0 . 9 3 6}$ \\
\hline
\end{tabular}

The values in the diagonal of the table represent the $\sqrt{ }$ AVE values

$E O U$ Perceived ease of use, $S C$ sunk cost, RES Resistance towards adoption of AIVA, RA regret avoidance, IN Inertia, $S W C$ switching cost, $P T$ perceived threat, $P V$ perceived value, $A T T$ attitude towards AIVA, $P U$ perceived usefulness

\begin{tabular}{llllllll}
\hline Groups & Model & $\chi^{2}$ & $\mathrm{df}$ & $\Delta \chi^{2}$ & $\Delta \mathrm{df}$ & RMSEA & CFI \\
\hline \multirow{4}{*}{ Gender } & Base model & 1098.121 & 385 & & & 0.066 & 0.955 \\
& Configural invariance & 1493.323 & 770 & $395.202 \mathrm{~ns}$ & 385 & 0.052 & 0.944 \\
& Metric invariance & 1525.439 & 801 & $32.116 \mathrm{~ns}$ & 31 & 0.053 & 0.940 \\
\multirow{4}{*}{ Age } & Scalar invariance & 1565.195 & 832 & $39.756 \mathrm{~ns}$ & 31 & 0.056 & 0.938 \\
& Configural invariance & 1515.242 & 770 & $417.121 \mathrm{~ns}$ & 385 & 0.050 & 0.949 \\
& Metric invariance & 1586.555 & 832 & $71.313 \mathrm{~ns}$ & 62 & 0.048 & 0.950 \\
& Scalar invariance & 1623.899 & 863 & $37.344 \mathrm{~ns}$ & 31 & 0.048 & 0.948 \\
\hline
\end{tabular}

Table 4 Measurement invariance analysis

\subsection{Multi-group Analysis Results}

The results concerning multi-group analysis for gender (male/female) are presented in Table 6. The table shows the path estimates for males and females differently, along with the estimate difference (z-score). It can be seen that three of nine path estimates differ between the male and female segment at a 95\% confidence level. Among all the paths, the relationship between perceived value and resistance showed a highly significant difference $(<0.01)$ between male and female samples with a z-score of 4.09. Notably, the relationship between perceived value and resistance is found to be insignificant for the female sample. Similarly, the relationship between regret avoidance and resistance is found to be insignificant for males but significant for the female sample. Importantly, the relationship between inertia and resistance is found to be insignificant for both the samples.

The multi-group analysis results for age groups can also be found in Table 6 . The findings highlight that generally these results were insignificant except for four paths identified. One of the major findings is that the relationship between ease of use and attitude is significantly different between old and young samples. However, it was found that the relationship is significant for both samples. Another 
Table 5 Standardised Estimates of the proposed model

\begin{tabular}{|c|c|c|c|c|c|}
\hline Hypotheses & Exogenous variable & Endogenous variable & Coefficient & $\mathrm{P}$-value & $r^{2}$ \\
\hline Hypothesis 1 & Sunk cost & $\begin{array}{l}\text { Resistance towards adop- } \\
\text { tion of AIVA }\end{array}$ & 0.212 & $<0.01$ & 0.465 \\
\hline Hypothesis 2 & Regret avoidance & & 0.119 & $<0.01$ & \\
\hline Hypothesis 3 & Inertia & & 0.064 & 0.150 & \\
\hline Hypothesis 4 & Perceived value & & -0.254 & $<0.01$ & \\
\hline Hypothesis 5 & Switching cost & & 0.244 & $<0.01$ & \\
\hline Hypothesis 6 & Perceived threat & & 0.280 & $<0.01$ & \\
\hline Hypothesis 7 & Perceived ease of use & Attitude towards AIVA & 0.307 & $<0.01$ & 0.372 \\
\hline Hypothesis 8 & Perceived usefulness & & 0.197 & $<0.01$ & \\
\hline Hypothesis 9 & Resistance towards AI & & -0.199 & $<0.01$ & \\
\hline
\end{tabular}

important result is that the relationship between inertia and resistance is higher with the older sample but negatively associated with the young sample. Similarly, regret avoidance was insignificant for the old sample, but not for the young sample. A detailed discussion about the results is presented in the subsequent sections.

\section{Discussion}

This research proposed a theoretical model consisting of eleven hypotheses, framed within the theoretical scope of the dual-factor theory, SQ theory, and TAM. The present study proposed a dual-factor model employing inhibitors (sunk cost, regret avoidance, inertia, switching costs, and perceived threat) and enablers (perceived value, perceived ease of use, and perceived usefulness) to investigate its relationship with resistance towards adoption of AIVA and attitude towards AIVA respectively. A total of 420 samples were analysed using SEM and the results of the hypotheses are presented in the above section. Eight out of nine proposed hypotheses were supported, and the model exhibited an adequate fit. Further to model evaluation, the study also employed hypotheses 10 and 11 , which investigated the impact of gender and age within the proposed model.

The model fit indices and the $r^{2}$ values of the dependent variables showed the strength of the model. To our knowledge, the study's hypotheses has not previously been investigated in the context of AI-powered voice assistants and only limited studies have explored this in the context of technology innovations. However, there are related studies that can lend a comparable view of the hypotheses. Hypothesis 1 and 2 investigated the relationship of sunk cost and regret avoidance with resistance towards adoption of AIVA. The result concerning sunk cost is consistent with previous studies that have investigated these aspects within an IS context (Kim \& Kankanhalli, 2009). The result of hypothesis 1 suggests that due to the fact that IS users have invested a considerable amount of time and cost in their existing system, this influences them to resist the adoption of AIVA. The results associated with regret avoidance are found to be positively related to resistance. Regret avoidance is mostly connected with the dissonance factor; the results indicate that IS users demonstrate resistance associated with the dissonant factor caused due to adopting new technology. So, both the cost invested with the present technology and the dissonance factors can increase levels of the resistance. This study's results are consistent with the previous study (Kim \& Kankanhalli, 2009), which investigated the variables in the context of IS implementation. Although the results of $\mathrm{H} 1$ and $\mathrm{H} 2$ are consistent with the IS literature, the results were not previously investigated in the context of AIVA. Despite the significance of the results, the standardized coefficients of $\mathrm{H} 1$ and $\mathrm{H} 2$ are within the range of 0.119 to 0.212 , which shows a very conservative relationship compared to previous studies that have investigated this topic. The results also represent the role of psychological commitment as a whole in developing resistance towards adopting AIVA. The users of AIVA might consider that there is no much investment involved with their existing technology and their knowledge toward AIVA may be considerably high. This in turn may have resulted in weak roles of sunk cost and regret avoidance respectively.

The negative relationship between perceived value and resistance towards adoption of AIVA explains the importance of the benefits this technology offers. The study's results are consistent with the existing literature, which has investigated similar relationships within an IS context (Kim \& Kankanhalli, 2009). However there is no study that has specifically investigated the relationship between perceived value and resistance in the context of AIVA. The results show that users value AIVA considerably highly which can reduce levels of resistant to adoption. The results associated with inertia are surprising and align with previous studies where researches have emphasized the significant role of inertia in creating resistance (Li et al., 2016). The insignificant relationship may be due to the dynamic changes from technology adoption. Nysveen et al. (2020) highlights that users are becoming more accepting of changes relating to 


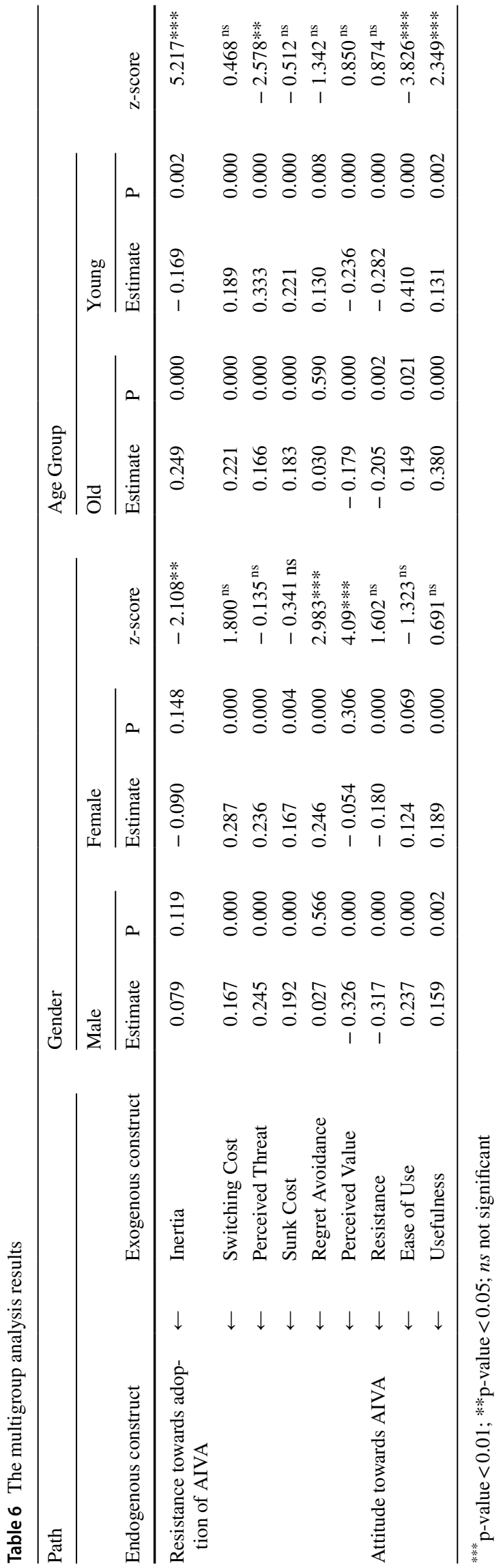

technology. Moreover, the result may be due to psychological acceptance towards technology has increased in recent times (Lamela et al., 2020). The results concerning inertia also explains that cognitive misperception partially failed to create resistance in adopting AIVA.

The result of hypothesis 5 indicates a significant positive relationship between switching cost and resistance. This result is supported via the previous literature where similar results exhibit consistency with these findings (Kim \& Kankanhalli, 2009). The result concerned with $\mathrm{H} 5$ explains how the users perceive the transition cost factor while switching over to AI voice assistants. Ghazali et al. (2016) reiterated a similar view that AI transition may involve considerable switching costs. The result of hypothesis 6 found that perceived threat established a significant relationship with resistance. Hsieh and Lin (2018) found similar results in the context of healthcare device technology but omitted to investigate the relationship in the context of AIVA. Various studies have questioned the uncertainty and security aspects that prevail within AI devices (Hengstler et al., 2016). AI devices have enhanced levels of uncertainty from users that could lead to resistance in adopting AIVA, the results from this study confirm the findings from the Hengstler study.

While many of the hypotheses have not been sufficiently explored before, the two hypotheses (hypothesis 7 and 8) have been investigated differently. The hypotheses (7 and 8) showed that PU and PEU have a significant relationship with attitude towards AIVA; this result is consistent with previous research (Abdullah et al., 2016). PEU is found to be highly significant with the attitude towards AIVA. The results show on how AI voice assistants have made the users' life easy. Though PU is significant with attitude, the standardized coefficient of the hypothesis (H8) is less than 0.2. This result may be due to the technology growth, in which users tend to give more importance to the effort reduction rather than the performance of the IS. The relationship between resistance and attitude is not previously explored. This study confirms that resistance can lead to a negative attitude towards AI voice assistants. User resistance is built dominantly by cognitive factors. Similarly, disposition towards technology is also a cognitive positioning that users can build. The results imply that the cognitive thought process underlying resistance and attitude is the major driver in this relationship.

The difference in estimates between the male/female sample and the young/old sample is a significant finding. The relationship between inertia and resistance is insignificant between gender groups but significant between age groups. This shows that both male and female users are cognitively susceptible to change. This can be elaborated from the results of the age groups. The results showed that the young sample is cognitively more susceptible to change, whereas the older demographic sample exhibits high cognitive inertia leading to resistance. Wang et al. (2020) supported a similar 
perspective. However, this study identified the relationship between perceived threat and resistance being higher for younger age groups than older users. Though various studies have supported that old age groups tend to exhibit reticence toward technology advancement (Astell et al., 2020), these studies have not been investigated this within the AI context. The multi-function level available at the AI level (Hengstler et al., 2016) and the young age group's usage intensity (Moore, 2012) can be the major reasons that could trigger higher perceived threat among the younger age groups when compared to the older sample. It was found that the relationship between regret avoidance and resistance is insignificant for males and older age groups. Byrnes et al. (1999) found that males seem to demonstrate a propensity to take on more risk than females. From this observation, it can be conceptualised that male users might have reduced levels of fear and therefore, a lower regret avoidance for resistance. In case of older age group, Warburton and Terry (2000) found that older age groups are more confident in their decisionmaking. The confidence and control exhibited by older age group users could limit their regret avoidance. Nevertheless, there is no previous study that can be directly referred to in the above results.

\subsection{Theoretical Contributions}

The study offers various theoretical implications. First, the study has incorporated the dual-factor model by integrating SQB theory and TAM, especially for examining AI devices. Given that very limited studies have tried to incorporate the dual-factor model in IS research, this study has proposed a collaborative model that includes both inhibitors and enablers. This incorporation we assert-adds value to existing literature. For example, Lin et al. (2015) used constraint and dedication factors to build loyalty towards IT products using the dual-factor approach. The present study will help the IS researchers to compare the constraints factors with SQB factors and dedication factors with PE and PEU. Thus a holistic idea can arrive at an extent.

Similarly, apart from IS research, the dual-factor model approach is necessary to understand any phenomenon's positive and negative implications, especially within IS genres. Secondly, this study has extended the application of SQB theory from the perspective of AIVA. Given the similarity between different AI devices, the study results can also extend to AI devices' available knowledge. More than as a comprehensive theory, this research has also given a micro-level perspective on the variables sunk cost, regret avoidance, inertia, perceived value, switching costs, and perceived threat. The variables-inertia and switching costs have received more attention in the literature than the remaining variables within IS research (Lucia-Palacios et al., 2016; Polites \& Karahanna, 2012). Likewise, based on the variable's nature, each one has received attention in relevant fields besides IS research thereby adding value in other disciplines.

This study has identified the significant negative relationship between resistance towards adoption of AIVA and attitude toward AIVA. The extant literature has mostly positioned attitude from the perspective of TPB or TRA. Though many studies tried to extend these theories to identify the negatively associated variables with attitude, this study adds value by unveiling the negative association between resistance and attitude. This research has investigated the role of gender and age group within the proposed model, whereas most of the existing literature seems to have used gender and age group as either moderating variable or as a control variable (Cai et al., 2017), this study has compared the estimates between gender and age. Previous studies have found that perceived usefulness will lead to a positive attitude; this study will allow the readers to contrast the difference in the relationship between gender and age groups. Thus, the results of RQ3 offer good value addition to the literature concerning SQB theory and TAM by providing an extended idea of how the hypotheses of the theories can differ across the gender and age groups.

This research has incorporated additional theories such as cognitive psychology theory and rational choice theory to position our hypotheses. The constructs belonging to the psychological commitment and cognitive misperception are derived from the existing knowledge from cognitive psychology theories. Cognitive dissonance theory is extensively used alongside consumer behaviour frameworks. The results concerning sunk cost and regret avoidance can add value to the existing knowledge in cognitive dissonance theory, especially the marketing domain, by emphasizing sunk cost and regret avoidance towards resistance. Similarly, the results of the switching costs and the perceived threat will extend the existing knowledge available in the literature related to rational choice theory. Importantly, the study investigated the adoption and resistance of AIVA from the end-user perspective. But on the other hand, previous studies have acknowledged that AI based applications are important in the business value chain (Chiu et al., 2021; Mikalef \& Gupta, 2021). So, this study extends a preliminary understanding that can benefit organization level adoption towards AIVA. The theories employed in this research have provided a holistic idea about the end-users attitudes towards AIVA, the understanding will allow the organisations to position their value offerings accordingly.

\subsection{Practical Contributions}

The resultsin this study can offer insight to practitioners, especially for IS managers and marketers to appropriately 
prepare their strategic plans. The following strategic points are discussed in this section based on the results of the study; (1) strategy to overcome resistance to AIVA, (2) focus on increasing the adoption level of AIVA, and (3) optimizing tool for different market segments.

The results indicated that perceived threat is one of the major variables that build resistance towards AIVA. The same results are reiterated in the opinion pool given in Table 1 and Appendix 2, where 38\% of the respondents rate privacy concerns as a dark factor in voice assistants. IS managers need to provide transparency in the system to address the privacy concerns. The literature has emphasized AIVA as a recognized home device, which is open to all functions. However, at the same time, the data is another crucial thought process that haunts users (Pappas et al., 2020). Researches have argued for various regulatory steps necessary to implement AI devices (Demlehner et al., 2021; Mazurek \& Małagocka, 2019). IS managers should start focusing on creating a transparent system alongside a performance-oriented system. Schmidt et al. (2020) emphasized the importance of transparency in AI; the paper also provides a comprehensive outlook that can help IS managers incorporate a strategic approach. Marketers can design their marketing communications with a focus on emphasising transparency and ethical policies in AI devices. This process can build a larger market for AIVA. Moreover, marketers should try to reduce the switching cost, and this can be obtained if AIVA is made available across more devices. This approach can reduce the exclusive transition costs necessary to adopt AIVA.

Ease of use is understood to be an important variable compared to usefulness. The results can be understood from two perspectives; users have perceived AIVA to reduce their efforts, or the users have not realized the potential of AIVA to the fullest. Most of the AI devices have been made to attract users in terms of effort reduction (Pappas \& Woodside, 2021). However, this study's results offer contribution and insight for IS managers to optimize the AIVA to its fullest potential. Again, marketers can optimize their communication to bring more functional appeals than peripheral appeals. Gender and age has a role in the resistance and attitude towards AIVA and is considerably explored within this study. From the perspective of IS managers and marketers it can be observed that users are psychologically adaptable to change and exhibit improvised; inertia and regret avoidance. IS researchers can optimize different functions and gender-based infrastructure in AIVA to position the value appropriate to each segment.

\subsection{Limitations and Future Research Directions}

The study employed a cross-sectional design to investigate the research questions, given if a factorial experimental design has been implemented, the results would have established a more causal effect. Although we narrowed our study design to the exact representative population, we still did not control the users previous AI experience to arrive at a representative score. However, since gender and age group differences were explored, in our view this provided a more comprehensive view of the results. Based on the literature exploration, results, and limitations, the following future research avenues exist: (1). The relationship between perceived value and resistance is found to be insignificant with the female sample, therefore future researchers could try to frame their research in this area. Given the AIVA employs anthropomorphic characteristics, it will be fruitful to investigate the role of gender stereotyping and user perception. (2). This research has employed SBQ factors as inhibitors and TAM as enablers, and future research can attempt to frame the dual-factor models with different inhibitors and enablers to arrive at a different perspective. For example: TAM 2 proposed by Venkatesh and Davis (2000) can be tested as enablers (3). The results concerning inertia have to be dealt with in detail with the help of future investigations. Future research should investigate whether inertia is still an important factor in technology resistance. It is important to realise whether inertia can play a mediating role in the resistance model. (4). While the role of AI has become omnipresent across the globe, very limited attention was given to emerging markets. Given the population and the potential market of Asian countries, future research should understand more about these users. (5). Finally, during the qualitative exploration, this study has identified six factors that describe user attitudes towards AIVA, among which most of the variables are not operationalized as constructs or rather integrated with any technology-related model. Future researches can address this major gap.

\section{Conclusion}

This research investigated the inhibitors and enablers underlying the adoption of AIVA. The study deployed SBQ theory and TAM within the framework of dual-factor modelling. We found that perceived value is a potential enabler which can reduce users resistance to adopting AIVA. Also, while, most of the studies have supported that inertia as a major barrier for technology adoption, this study confirms that younger users are more susceptible to the impacts of change compared to the older age group. Moreover it was found that inertia is insignificant to create resistance for both the gender groups. Thus, the results of our study provides a holistic picture to understand the enablers and inhibitors that are present in the AIVA. 


\section{Appendix 1: Details of the scale for each item}

\begin{tabular}{|c|c|c|}
\hline Construct & Scale & Source(s) \\
\hline Sunk cost & $\begin{array}{l}\text { I have already invested a lot of time learning to use my existing } \\
\text { technology with the functions like home assistance, controlling } \\
\text { home devices, and other functions that AI-based voice assistants } \\
\text { are capable of providing } \\
\text { I have already invested a lot of time in perfecting my skills at using } \\
\text { my existing technology items with the functions such as home } \\
\text { assistance, controlling home devices, and other functions which } \\
\text { AI based voice assistants are capable of providing }\end{array}$ & $\begin{array}{l}\text { Polites and Karahanna (2012); Tsiros and } \\
\text { Mittal (2000); Kim and Kankanhalli (2009); } \\
\text { Bhattacherjee and Hikmet (2007); Hsieh } \\
\text { (2015) }\end{array}$ \\
\hline Regret avoidance & $\begin{array}{l}\text { I will feel regret for choosing AI based Voice Assistants } \\
\text { I will feel more regret for bad outcomes that are the consequences } \\
\text { of new actions taken }\end{array}$ & \\
\hline Inertia & $\begin{array}{l}\text { I will continue using my existing technology options for functions } \\
\text { such as home assistance, controlling home devices, and other } \\
\text { functions that AI based voice assistants are capable of providing } \\
\text { Because the change to AI based voice assistants would be stressful } \\
\text { Because I enjoy engaging with my existing technology } \\
\text { I acknowledge that my current technology is not the best way of } \\
\text { doing things }\end{array}$ & \\
\hline Perceived value & $\begin{array}{l}\text { Considering the time and effort I have to invest, changing to the AI } \\
\text { based Voice Assistants way of working is worthwhile } \\
\text { Considering any perceived or incurred losses, changing to the AI } \\
\text { based Voice Assistants is of good value } \\
\text { Considering the inconvenience I may have to incure, changing to } \\
\text { the AI based voice assistants is beneficial to me }\end{array}$ & \\
\hline Switching costs & $\begin{array}{l}\text { I have already invested a significant amount of time and effort } \\
\text { mastering the current way of working } \\
\text { It would take a lot of time and effort for me to switch to the AI } \\
\text { based voice assistants } \\
\text { Switching to the AI based voice assistants could result in unex- } \\
\text { pected additional work or effort }\end{array}$ & \\
\hline Perceived threat & $\begin{array}{l}\text { I fear that I may lose control over the way I work if I started using } \\
\text { AI-based voice assistants } \\
\text { I fear the uncertainty, confidentiality and security aspects of AI- } \\
\text { based voice assistants } \\
\text { Overall, I consider the adoption of AI-based voice assistants to be } \\
\text { risky }\end{array}$ & \\
\hline Perceived ease of use & $\begin{array}{l}\text { I feel AI-based voice assistants are easy to use } \\
\text { I feel learning to operate AI-based voice assistants is easy } \\
\text { Overall, I believe it is easy to work with AI-based voice assistants }\end{array}$ & Hsu and Lin (2008) \\
\hline Perceived usefulness & $\begin{array}{l}\text { Using AI-based voice assistants enables me to accomplish my } \\
\text { work/learning/life more quickly } \\
\text { Using AI-based voice assistants would improve my work/learning/ } \\
\text { life performance } \\
\text { Using AI-based voice assistants would enhance my work/learning/ } \\
\text { life effectiveness } \\
\text { Using AI-based voice assistants can increase my productivity when } \\
\text { performing my tasks at work/learning/life }\end{array}$ & \\
\hline Attitude towards AIVA & $\begin{array}{l}\text { I like using AI-based voice assistants } \\
\text { I feel good about using AI-based voice assistants } \\
\text { Overall, my attitude towards AI-based voice assistants is favourable }\end{array}$ & \\
\hline Resistance towards AIVA & $\begin{array}{l}\text { I will not comply with the change to the new way of working with } \\
\text { functions such as home assistance, controlling home devices, and } \\
\text { other functions that AI-based voice assistants can provide }\end{array}$ & $\begin{array}{l}\text { Kim and Kankanhalli (2009) and Bhattacher- } \\
\text { jee and Hikmet (2007) }\end{array}$ \\
\hline
\end{tabular}




\begin{tabular}{ll}
\hline Construct & Scale \\
\hline I will not cooperate with the change to new ways of working for \\
functions such as home assistance, controlling home devices, and \\
other functions that AI-based voice assistants can provide \\
I oppose the change to the new ways of working with functions \\
such as home assistance, controlling home devices, and other \\
functions that AI-based voice assistants can provide \\
I do not agree with the change to new ways of working with func- \\
tions such as home assistance, controlling home devices, and \\
other functions that AI-based voice assistants can provide \\
\hline
\end{tabular}

\section{Appendix 2}

See Figure 2.

Fig. 2 Factors that insist likingness and resistance towards voice assistants collected from the 420 sample
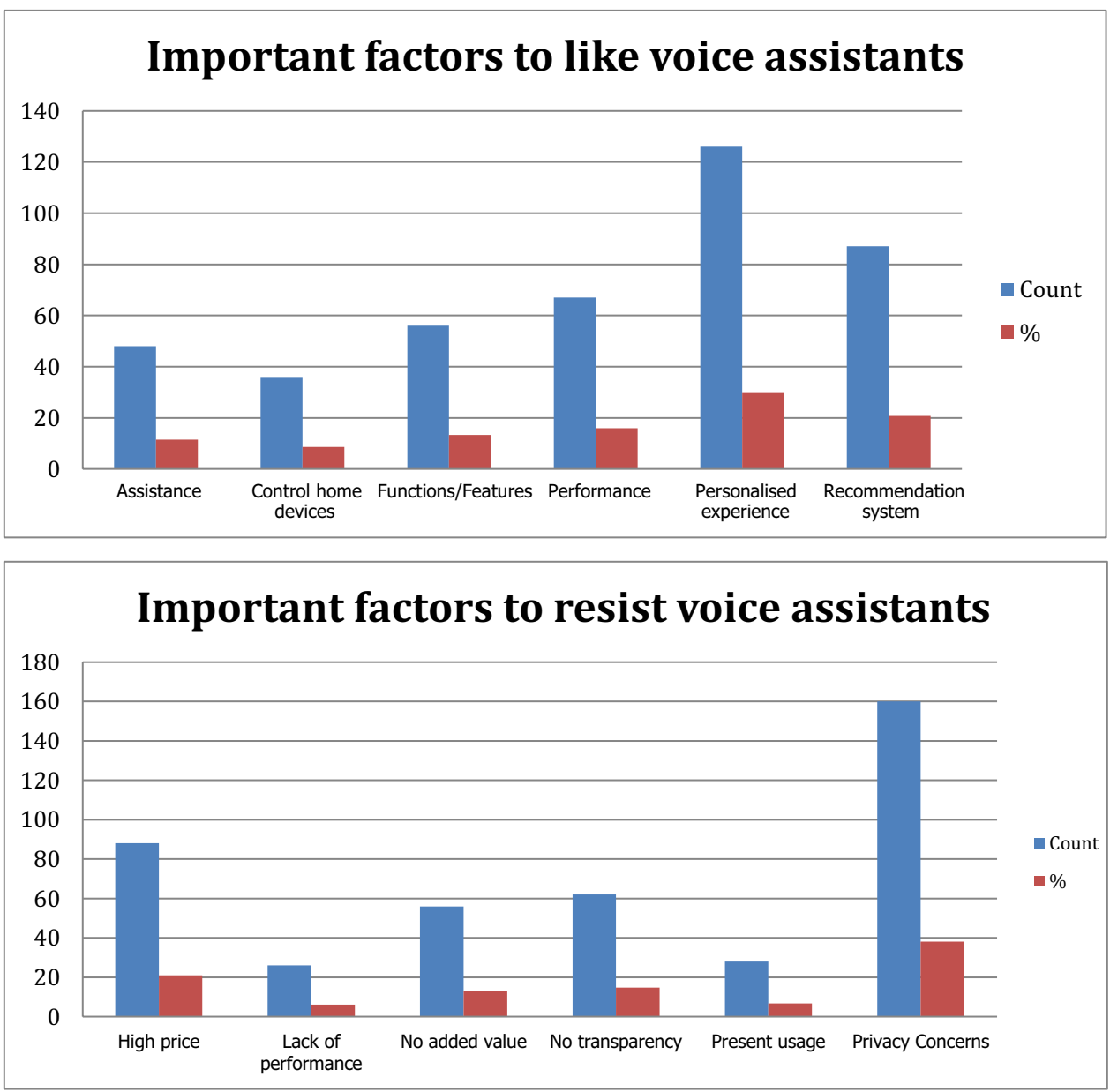
Open Access This article is licensed under a Creative Commons Attribution 4.0 International License, which permits use, sharing, adaptation, distribution and reproduction in any medium or format, as long as you give appropriate credit to the original author(s) and the source, provide a link to the Creative Commons licence, and indicate if changes were made. The images or other third party material in this article are included in the article's Creative Commons licence, unless indicated otherwise in a credit line to the material. If material is not included in the article's Creative Commons licence and your intended use is not permitted by statutory regulation or exceeds the permitted use, you will need to obtain permission directly from the copyright holder. To view a copy of this licence, visit http://creativecommons.org/licenses/by/4.0/.

\section{References}

Abdullah, F., Ward, R., \& Ahmed, E. (2016). Investigating the influence of the most commonly used external variables of TAM on students' Perceived Ease of Use (PEOU) and Perceived Usefulness (PU) of e-portfolios. Computers in Human Behavior, 63 , 75-90.

Alalwan, A. A., Baabdullah, A. M., Rana, N. P., Tamilmani, K., \& Dwivedi, Y. K. (2018). Examining adoption of mobile internet in Saudi Arabia: Extending TAM with perceived enjoyment, innovativeness and trust. Technology in Society, 55, 100-110.

Anderson, J. C., \& Gerbing, D. W. (1988). Structural equation modeling in practice: A review and recommended two-step approach. Psychological Bulletin, 103(3), 411.

Astell, A. J., McGrath, C., \& Dove, E. (2020). "That's for old so and so's!": Does identity influence older adults' technology adoption decisions? Ageing \& Society, 40(7), 1550-1576.

Bagozzi, R. P., Yi, Y., \& Phillips, L. W. (1991). Assessing construct validity in organizational research. Administrative Science Quarterly, 36(3), 421-458.

Balakrishnan, J., \& Dwivedi, Y. K. (2021a). Role of cognitive absorption in building user trust and experience. Psychology \& Marketing, 38(4), 643-668.

Balakrishnan, J., \& Dwivedi, Y. K. (2021b). Conversational commerce: Entering the next stage of AI-powered digital assistants. Annals of Operations Research. https://doi.org/10.1007/ s10479-021-04049-5

Bawack, R. E., Wamba, S. F., \& Carillo, K. D. A. (2021). Exploring the role of personality, trust, and privacy in customer experience performance during voice shopping: Evidence from SEM and fuzzy set qualitative comparative analysis. International Journal of Information Management, 58, 102309.

Besson, P., \& Rowe, F. (2012). Strategizing information systems-enabled organizational transformation: A transdisciplinary review and new directions. The Journal of Strategic Information Systems, 21(2), 103-124.

Bhattacherjee, A., \& Hikmet, N. (2007). Physicians' resistance toward healthcare information technology: A theoretical model and empirical test. European Journal of Information Systems, 16(6), $725-737$.

Borges, A. F., Laurindo, F. J., Spínola, M. M., Gonçalves, R. F., \& Mattos, C. A. (2021). The strategic use of artificial intelligence in the digital era: Systematic literature review and future research directions. International Journal of Information Management, 57,102225

Bollen, K. A. (1989). Structural equations with latent variables. Wiley. Brehm, J. W., \& Cohen, A. R. (1962). Explorations in cognitive dissonance. Wiley. https://doi.org/10.1037/11622-000

Brehm, J. W., \& Wicklund, R. A. (1970). Regret and dissonance reduction as a function of postdecision salience of dissonant information. Journal of Personality and Social Psychology, 14(1), 1-7.
Bulgurcu, B., Cavusoglu, H., \& Benbasat, I. (2010). Information security policy compliance: An empirical study of rationality-based beliefs and information security awareness. MIS Quarterly, 34(3), 523-548.

Burmeister, K., \& Schade, C. (2007). Are entrepreneurs' decisions more biased? An experimental investigation of the susceptibility to status quo bias. Journal of Business Venturing, 22(3), 340-362.

Burnham, T. A., Frels, J. K., \& Mahajan, V. (2003). Consumer switching costs: A typology, antecedents, and consequences. Journal of the Academy of Marketing Science, 31(2), 109-126.

Byrne, B. (2010). Structural equation modeling with AMOS: Basic concepts, applications and programming (6th ed.). Taylor \& Francis.

Byrnes, J. P., Miller, D. C., \& Schafer, W. D. (1999). Gender differences in risk taking: A meta-analysis. Psychological Bulletin, 125(3), 367.

Cai, Z., Fan, X., \& Du, J. (2017). Gender and attitudes toward technology use: A meta-analysis. Computers \& Education, 105, 1-13.

Cao, G., Duan, Y., Edwards, J. S., \& Dwivedi, Y. K. (2021). Understanding managers' attitudes and behavioral intentions towards using artificial intelligence for organizational decision-making. Technovation, 106, 102312.

Cenfetelli, R. T. (2004). Inhibitors and enablers as dual factor concepts in technology usage. Journal of the Association for Information Systems, 5(11), 16.

Chaouali, W., \& Souiden, N. (2019). The role of cognitive age in explaining mobile banking resistance among elderly people. Journal of Retailing and Consumer Services, 50, 342-350.

Chi, O. H., Denton, G., \& Gursoy, D. (2020). Artificially intelligent device use in service delivery: A systematic review, synthesis, and research agenda. Journal of Hospitality Marketing \& Management, 29(7), 757-786.

Chui, M., Manyika, J., Miremadi, M., Henke, N., Chung, R., Nel, P., \& Malhotra, S. (2018). Notes from the AI frontier: Insights from hundreds of use cases. McKinsey Global Institute. Retrieved December 15, 2020, from, https://www.mckinsey.com/ /media/ mckinsey/featured\%20insights/artificial\%20intelligence/notes\% 20 from $\% 20$ the $\% 20$ ai $\% 20$ frontier\%20applications $\% 20$ and $\% 20$ val ue\%20of\%20deep\%20learning/notes-from-the-ai-frontier-insig hts-from-hundreds-of-use-cases-discussion-paper.ashx.

Chung, S. H., \& Cheng, K. C. (2018). How does cognitive dissonance influence the sunk cost effect? Psychology Research and Behavior Management, 11, 79-80.

Chiu, Y. T., Zhu, Y. Q., \& Corbett, J. (2021). In the hearts and minds of employees: A model of pre-adoptive appraisal toward artificial intelligence in organizations. International Journal of Information Management, 60, 102379.

Collins, C., Dennehy, D., Conboy, K., \& Mikalef, P. (2021). Artificial intelligence in information systems research: A systematic literature review and research agenda. International Journal of Information Management, 60, 102383.

Coombs, C. (2020). Will COVID-19 be the tipping point for the intelligent automation of work? A review of the debate and implications for research. International Journal of Information Management, 55, 102182.

Dang, Y. M., Zhang, Y. G., \& Morgan, J. (2017). Integrating switching costs to information systems adoption: An empirical study on learning management systems. Information Systems Frontiers, 19(3), 625-644.

Davis, F. D. (1989). Perceived usefulness, perceived ease of use, and user acceptance of information technology. MIS Quarterly, 13(3), 319-340.

Davis, F. D., Bagozzi, R. P., \& Warshaw, P. R. (1989). User acceptance of computer technology: A comparison of two theoretical models. Management Science, 35(8), 982-1003. 
Del Val, M. P., \& Fuentes, C. M. (2003). Resistance to change: A literature review and empirical study. Management Decision, 41(2), 148-155.

Demlehner, Q., Schoemer, D., \& Laumer, S. (2021). How can artificial intelligence enhance car manufacturing? A Delphi study-based identification and assessment of general use cases. International Journal of Information Management, 58, 102317.

Duan, Y., Edwards, J. S., \& Dwivedi, Y. K. (2019). Artificial intelligence for decision making in the era of Big Data-evolution, challenges and research agenda. International Journal of Information Management, 48, 63-71.

Dwivedi, Y. K., Hughes, L., Ismagilova, E., Aarts, G., Coombs, C., Crick, T., ... \& Williams, M. D. (2021a). Artificial Intelligence (AI): Multidisciplinary perspectives on emerging challenges, opportunities, and agenda for research, practice and policy. International Journal of Information Management. 57, 101994.

Dwivedi, Y. K., Ismagilova, E., Hughes, D. L., Carlson, J., Filieri, R., Jacobson, J., ... \& Wang, Y. (2021b). Setting the future of digital and social media marketing research: Perspectives and research propositions. International Journal of Information Management, 59, 102168. https://doi.org/10.1016/j.ijinfomgt.2020.10216

Dwivedi, Y. K., Rana, N. P., Jeyaraj, A., Clement, M., \& Williams, M. D. (2019). Re-examining the unified theory of acceptance and use of technology (UTAUT): Towards a revised theoretical model. Information Systems Frontiers, 21(3), 719-734.

Elias, S. M., Smith, W. L., \& Barney, C. E. (2012). Age as a moderator of attitude towards technology in the workplace: Work motivation and overall job satisfaction. Behaviour \& Information Technology, 31(5), 453-467.

Faul, F., Erdfelder, E., Buchner, A., \& Lang, A. G. (2009). Statistical power analyses using $\mathrm{G}^{*}$ Power 3.1: Tests for correlation and regression analyses. Behavior Research Methods, 41(4), $1149-1160$.

Fernandes, T., \& Oliveira, E. (2021). Understanding consumers' acceptance of automated technologies in service encounters: Drivers of digital voice assistants adoption. Journal of Business Research, 122, 180-191.

Fornell, C., \& Larcker, D. F. (1981). Evaluating structural equation models with unobservable variables and measurement error. Journal of Marketing Research, 18(4), 39-50.

Gefen, D., Karahanna, E., \& Straub, D. W. (2003). Inexperience and experience with online stores: The importance of TAM and trust. IEEE Transactions on Engineering Management, 50(3), 307-321.

Ghazali, E., Nguyen, B., Mutum, D. S., \& Mohd-Any, A. A. (2016). Constructing online switching barriers: Examining the effects of switching costs and alternative attractiveness on e-store loyalty in online pure-play retailers. Electronic Markets, 26(2), 157-171.

Grover, P., Kar, A. K., \& Dwivedi, Y. K. (2020). Understanding artificial intelligence adoption in operations management: Insights from the review of academic literature and social media discussions. Annals of Operations Research. https://doi.org/10.1007/ s10479-020-03683-9

Gursoy, D., Chi, O. H., Lu, L., \& Nunkoo, R. (2019). Consumers acceptance of artificially intelligent (AI) device use in service delivery. International Journal of Information Management, 49, 157-169.

Hair, J. F., Sarstedt, M., Ringle, C. M., \& Mena, J. A. (2012). An assessment of the use of partial least squares structural equation modeling in marketing research. Journal of the Academy of Marketing Science, 40(3), 414-433.

Han, S., \& Yang, H. (2018). Understanding adoption of intelligent personal assistants. Industrial Management \& Data Systems, 118(3), 618-636.

Han, S.L., An, M.A., Han, J.J., Lee, J. (2018). Underlying factors of virtual reality shopping and moderating effects of time distortion:
Extension of the virtual liminoid theory. In: In 2018 global marketing conference at Tokyo, pp. 271-273.

Hengstler, M., Enkel, E., \& Duelli, S. (2016). Applied artificial intelligence and trust-The case of autonomous vehicles and medical assistance devices. Technological Forecasting and Social Change, 105, 105-120.

Herzberg, F., Mausner, B., \& Snyderman, B. B. (1959). The motivation to work. Wiley.

Hsieh, P. J. (2015). Healthcare professionals' use of health clouds: Integrating technology acceptance and status quo bias perspectives. International Journal of Medical Informatics, 84(7), 512-523.

Hsieh, P. J., \& Lin, W. S. (2018). Explaining resistance to system usage in the PharmaCloud: A view of the dual-factor model. Information \& Management, 55(1), 51-63.

Hsu, C. L., \& Lin, J. C. C. (2008). Acceptance of blog usage: The roles of technology acceptance, social influence and knowledge sharing motivation. Information \& Management, 45(1), 65-74.

Hu, Q., Lu, Y., Pan, Z., Gong, Y., \& Yang, Z. (2021). Can AI artifacts influence human cognition? The effects of artificial autonomy in intelligent personal assistants. International Journal of Information Management, 56, 102250.

Kapoor, K. K., Tamilmani, K., Rana, N. P., Patil, P., Dwivedi, Y. K., \& Nerur, S. (2018). Advances in social media research: Past, present and future. Information Systems Frontiers, 20(3), 531-558.

Karl, F. M., Holle, R., Schwettmann, L., Peters, A., \& Laxy, M. (2019). Status quo bias and health behavior: Findings from a cross-sectional study. European Journal of Public Health, 29(5), 992-997.

Kendall, L., Chaudhuri, B., \& Bhalla, A. (2020). Understanding technology as situated practice: Everyday use of voice user interfaces among diverse groups of users in urban India. Information Systems Frontiers, 22, 585-605.

Khan, I., Hollebeek, L. D., Fatma, M., Islam, J. U., \& Riivits-Arkonsuo, I. (2020). Customer experience and commitment in retailing: Does customer age matter? Journal of Retailing and Consumer Services, 57, 102219.

Kim, H. W., \& Kankanhalli, A. (2009). Investigating user resistance to information systems implementation: A status quo bias perspective. MIS Quarterly, 33(3), 567-582.

Kim, S., \& Garrison, G. (2009). Investigating mobile wireless technology adoption: An extension of the technology acceptance model. Information Systems Frontiers, 11(3), 323-333.

Kline, R. B. (1998). Principles and practice of structural equation modeling. Guilford.

Klumpp, M. (2018). Automation and artificial intelligence in business logistics systems: Human reactions and collaboration requirements. International Journal of Logistics Research and Applications, 21(3), 224-242.

Koller, M., Floh, A., \& Zauner, A. (2011). Further insights into perceived value and consumer loyalty: A "green" perspective. Psychology \& Marketing, 28(12), 1154-1176.

Kumar, P., Dwivedi, Y. K., \& Anand, A. (2021). Responsible artificial intelligence $(\mathrm{AI})$ for value formation and market performance in healthcare: The mediating role of patient's cognitive engagement. Information Systems Frontiers. https://doi.org/10.1007/ s10796-021-10136-6

Kumar, V., Dixit, A., Javalgi, R. R. G., \& Dass, M. (2016). Research framework, strategies, and applications of intelligent agent technologies (IATs) in marketing. Journal of the Academy of Marketing Science, 44(1), 24-45.

Lamela, D., Cabral, J., Coelho, S., \& Jongenelen, I. (2020). Personal stigma, determinants of intention to use technology, and acceptance of internet-based psychological interventions for depression. International Journal of Medical Informatics, 136, 104076.

Lee, I. (2017). Big data: Dimensions, evolution, impacts, and challenges. Business Horizons, 60(3), 293-303. 
Lee, K., \& Joshi, K. (2017). Examining the use of status quo bias perspective in IS research: Need for re-conceptualizing and incorporating biases. Information Systems Journal, 27(6), 733-752.

Lemley, J., Bazrafkan, S., \& Corcoran, P. (2017). Deep learning for consumer devices and services: Pushing the limits for machine learning, artificial intelligence, and computer vision. IEEE Consumer Electronics Magazine, 6(2), 48-56.

Li, J., Liu, M., \& Liu, X. (2016). Why do employees resist knowledge management systems? An empirical study from the status quo bias and inertia perspectives. Computers in Human Behavior, 65, 189-200.

Lin, T. C., Huang, S. L., \& Hsu, C. J. (2015). A dual-factor model of loyalty to IT product-The case of smartphones. International Journal of Information Management, 35(2), 215-228.

Lines, R. (2004). Influence of participation in strategic change: Resistance, organizational commitment and change goal achievement. Journal of Change Management, 4(3), 193-215.

Lucia-Palacios, L., Pérez-López, R., \& Polo-Redondo, Y. (2016). Enemies of cloud services usage: Inertia and switching costs. Service Business, 10(2), 447-467.

MacKenzie, S. B., \& Podsakoff, P. M. (2012). Common method bias in marketing: Causes, mechanisms, and procedural remedies. Journal of Retailing, 88(4), 542-555.

Marikyan, D., Papagiannidis, S., \& Alamanos, E. (2020). Cognitive Dissonance in Technology Adoption: A Study of Smart Home Users. Information Systems Frontiers. https://doi.org/10.1007/ s10796-020-10042-3

Markus, M. L. (1983). Power, politics, and MIS implementation. Communications of the ACM, 26(6), 430-444.

Masatlioglu, Y., \& Ok, E. A. (2005). Rational choice with status quo bias. Journal of Economic Theory, 121(1), 1-29.

Mazurek, G., \& Małagocka, K. (2019). Perception of privacy and data protection in the context of the development of artificial intelligence. Journal of Management Analytics, 6(4), 344-364.

McLean, G., \& Osei-Frimpong, K. (2019). Hey Alexa... examine the variables influencing the use of artificial intelligent in-home voice assistants. Computers in Human Behavior, 99, 28-37.

Mikalef, P., Boura, M., Lekakos, G., \& Krogstie, J. (2019). Big data analytics and firm performance: Findings from a mixed-method approach. Journal of Business Research, 98, 261-276.

Mikalef, P., \& Gupta, M. (2021). Artificial intelligence capability: Conceptualization, measurement calibration, and empirical study on its impact on organizational creativity and firm performance. Information \& Management, 58(3), 103434.

Mikalef, P., van de Wetering, R., \& Krogstie, J. (2020). Building dynamic capabilities by leveraging big data analytics: The role of organizational inertia. Information \& Management. https:// doi.org/10.1016/j.im.2020.103412

Minsky, M. L. (1968). Semantic information processing. MIT Press.

MIT Technology Review (2019), Tiny AI models could supercharge autocorrect and voice assistants on your phone. Retrieved June 15, 2020, from https://www.technologyreview.com/f/ 614473/tiny-ai-could-supercharge-autocorrect-voice-assis tants-on-your-phone/.

Moon, H. (2001). Looking forward and looking back: Integrating completion and sunk-cost effects within an escalation-of-commitment progress decision. Journal of Applied Psychology, 86(1), 104.

Moore, M. (2012). Interactive media usage among millennial consumers. Journal of Consumer Marketing., 29(6), 436-444.

Moorman, C., Zaltman, G., \& Deshpande, R. (1992). Relationships between providers and users of market research: The dynamics of trust within and between organizations. Journal of Marketing Research, 29(3), 314-328.

Morin, A. J., Meyer, J. P., Bélanger, É., Boudrias, J. S., Gagné, M., \& Parker, P. D. (2016). Longitudinal associations between employees' beliefs about the quality of the change management process, affective commitment to change and psychological empowerment. Human Relations, 69(3), 839-867.

Morris, M. G., \& Venkatesh, V. (2000). Age differences in technology adoption decisions: Implications for a changing work force. Personnel Psychology, 53(2), 375-403.

Nebel, J. M. (2015). Status quo bias, rationality, and conservatism about value. Ethics, 125(2), 449-476.

Nunnally, J. C. (1978). Psychometric theory. Tata McGraw-Hill.

Nysveen, H., Pedersen, P. E., \& Skard, S. (2020). Ecosystem adoption of practices over time (EAPT): Toward an alternative view of contemporary technology adoption. Journal of Business Research, 116, 542-551.

Owen-Smith, J. (2001). Managing laboratory work through skepticism: Processes of evaluation and control. American Sociological Review, 66(3), 427-452.

Pappas, I. O., \& Woodside, A. G. (2021). Fuzzy-set qualitative comparative analysis (fsQCA): Guidelines for research practice in information systems and marketing. International Journal of Information Management, 58, 102310.

Pappas, I. O., Mikalef, P., Giannakos, M. N., Krogstie, J., \& Lekakos, G. (2018). Big data and business analytics ecosystems: Paving the way towards digital transformation and sustainable societies. Information Systems and e-Business Management, 16, 479-491.

Pappas, I. O., Papavlasopoulou, S., Mikalef, P., \& Giannakos, M. N. (2020). Identifying the combinations of motivations and emotions for creating satisfied users in SNSs: An fsQCA approach. International Journal of Information Management, 53, 102128.

Park, S., Hahn, S., Lee, T., \& Jun, M. (2018). Two factor model of consumer satisfaction: International tourism research. Tourism Management, 67, 82-88.

Paternoster, R., \& Pogarsky, G. (2009). Rational choice, agency and thoughtfully reflective decision making: The short and long-term consequences of making good choices. Journal of Quantitative Criminology, 25(2), 103-127.

Pearson, A., Tadisina, S., \& Griffin, C. (2012). The role of e-service quality and information quality in creating perceived value: Antecedents to web site loyalty. Information Systems Management, 29(3), 201-215.

Pillai, R., Sivathanu, B., \& Dwivedi, Y. K. (2020). Shopping intention at AI-powered automated retail stores (AIPARS). Journal of Retailing and Consumer Services, 57, 102207.

Plecher, H. (2020). "Median age of the population in India 2015", Retrieved December 15, 2020, from https://www.statista.com/ statistics/254469/median-age-of-the-population-in-india/\#: : text=The $\% 20$ median $\% 20$ age $\% 20$ in $\% 20$ India,38.1\%20years\% 20old $\% 20$ by $\% 202050$.

Podsakoff, P. M., MacKenzie, S. B., Lee, J. Y., \& Podsakoff, N. P. (2003). Common method biases in behavioral research: A critical review of the literature and recommended remedies. Journal of Applied Psychology, 88(5), 879.

Polites, G. L., \& Karahanna, E. (2012). Shackled to the status quo: The inhibiting effects of incumbent system habit, switching costs, and inertia on new system acceptance. MIS Quarterly, 36(1), 21-42.

Popovič, A., Hackney, R., Tassabehji, R., \& Castelli, M. (2018). The impact of big data analytics on firms' high value business performance. Information Systems Frontiers, 20(2), 209-222.

Portney, L. G., \& Watkins, M. P. (2000). Foundations of clinical research: Applications to practice. Prentice Hall Health.

Pronin, E. (2007). Perception and misperception of bias in human judgment. Trends in Cognitive Sciences, 11(1), 37-43.

PWC. (2018). Consumer intelligence series: Prepare for the voice revolution. Retrieved December 20, 2020, from https://www.pwc. com/us/en/advisory-services/publications/consumer-intelligen ce-series/voice-assistants.pdf. 
Rauyruen, P., \& Miller, K. E. (2007). Relationship quality as a predictor of B2B customer loyalty. Journal of Business Research, 60(1), 21-31.

Roy, S. K., Balaji, M. S., Quazi, A., \& Quaddus, M. (2018). Predictors of customer acceptance of and resistance to smart technologies in the retail sector. Journal of Retailing and Consumer Services, 42, 147-160.

Samuelson, W., \& Zeckhauser, R. (1988). Status quo bias in decision making. Journal of Risk and Uncertainity, 1(1), 7-59.

Santos, J., Rodrigues, J. J., Silva, B. M., Casal, J., Saleem, K., \& Denisov, V. (2016). An IoT-based mobile gateway for intelligent personal assistants on mobile health environments. Journal of Network and Computer Applications, 71, 194-204.

Schmidt, P., Biessmann, F., \& Teubner, T. (2020). Transparency and trust in artificial intelligence systems. Journal of Decision Systems, 29(4), 260-278.

Seetharaman, P., Mathew, S. K., Sein, M. K., \& Tallamraju, R. B. (2020). Being (more) human in a digitized world. Information Systems Frontiers. https://doi.org/10.1007/s10796-020-10020-9

Shareef, M. A., Kumar, V., Dwivedi, Y. K., Kumar, U., Akram, M. S., \& Raman, R. (2021). A new health care system enabled by machine intelligence: Elderly people's trust or losing self control. Technological Forecasting and Social Change, 162, 120334.

Shariff, A., Bonnefon, J. F., \& Rahwan, I. (2017). Psychological roadblocks to the adoption of self-driving vehicles. Nature Human Behaviour, 1(10), 694-696.

Sharma, S. K. (2019). Integrating cognitive antecedents into TAM to explain mobile banking behavioral intention: A SEM-neural network modeling. Information Systems Frontiers, 21(4), 815-827.

Sipior, J. C. (2020). Considerations for Development and Use of AI in Response to COVID-19. International Journal of Information Management, 55, 102170.

Steenkamp, J. B. E., \& Baumgartner, H. (1998). Assessing measurement invariance in cross-national consumer research. Journal of Consumer Research, 25(1), 78-90.

Steinberg, L., \& Monahan, K. C. (2007). Age differences in resistance to peer influence. Developmental Psychology, 43(6), 1531.

Suldo, S. M., Thalji-Raitano, A., Kiefer, S. M., \& Ferron, J. M. (2016). Conceptualizing high school students' mental health through a dual-factor model. School Psychology Review, 45(4), 434-457.

Sung, E. C., Bae, S., Han, D. I. D., \& Kwon, O. (2021). Consumer engagement via interactive artificial intelligence and mixed reality. International Journal of Information Management, 60, 102382.

Tam, C., Santos, D., \& Oliveira, T. (2020). Exploring the influential factors of continuance intention to use mobile Apps: Extending the expectation confirmation model. Information Systems Frontiers, 22(1), 243-257.

Tankovska, H. (2020). Number of digital voice assistants in use worldwide 2019-2024. Retrieved December 19, 2020, from https:// www.statista.com/statistics/973815/worldwide-digital-voiceassistant-in-use/.

Tanovic, E., Gee, D. G., \& Joormann, J. (2018). Intolerance of uncertainty: Neural and psychophysiological correlates of the perception of uncertainty as threatening. Clinical Psychology Review, 60, 87-99.

Tsiros, M., \& Mittal, V. (2000). Regret: A model of its antecedents and consequences in consumer decision making. Journal of Consumer Research, 26(4), 401-417.

Tussyadiah, I. (2020). A review of research into automation in tourism: Launching the Annals of Tourism Research Curated Collection on Artificial Intelligence and Robotics in Tourism. Annals of Tourism Research, 81, 102883.

Venkatesh, V., \& Davis, F. D. (2000). A theoretical extension of the technology acceptance model: Four longitudinal field studies. Management Science, 46(2), 186-204.
Vimalkumar, M., Sharma, S. K., Singh, J. B., \& Dwivedi, Y. K. (2021a). 'Okay google, what about my privacy?': User's privacy perceptions and acceptance of voice based digital assistants. Computers in Human Behavior, 120, 106763.

Vimalkumar, M., Gupta, A., Sharma, D., \& Dwivedi, Y. K. (2021b). Understanding the Effect that Task Complexity has on Automation Potential and Opacity: Implications for Algorithmic Fairness. AIS Transactions on Human-Computer Interaction, 13(1), 104-129.

Wang, D., Schneider, S., Schwartz, J. E., \& Stone, A. A. (2020). Heightened stress in employed individuals is linked to altered variability and inertia in emotions. Frontiers in Psychology, 11, 1152.

Warburton, J., \& Terry, D. J. (2000). Volunteer decision making by older people: A test of a revised theory of planned behavior. Basic and Applied Social Psychology, 22(3), 245-257.

Whitten, D., \& Wakefield, R. L. (2006). Measuring switching costs in IT outsourcing services. The Journal of Strategic Information Systems, 15(3), 219-248.

Wilson, H. J., \& Daugherty, P. R. (2018). Collaborative intelligence: Humans and AI are joining forces. Harvard Business Review, 96(4), 114-123.

Yang, C. G., \& Lee, H. J. (2016). A study on the antecedents of healthcare information protection intention. Information Systems Frontiers, 18(2), 253-263.

Zaltman, G., \& Duncan, R. (1977). Strategies for planned change. Wiley.

Zhang, X., Guo, X., Wu, Y., Lai, K. H., \& Vogel, D. (2017). Exploring the inhibitors of online health service use intention: A status quo bias perspective. Information \& Management, 54(8), 987-997.

Zhang, D., Pee, L. G., \& Cui, L. (2021). Artificial intelligence in E-commerce fulfillment: A case study of resource orchestration at Alibaba's Smart Warehouse. International Journal of Information Management, 57, 102304.

Publisher's Note Springer Nature remains neutral with regard to jurisdictional claims in published maps and institutional affiliations.

Janarthanan Balakrishnan is Assistant Professor in Department of Management Studies at National Institute of Technology, Tiruchirappalli. His research interests are in the area of psychology andmarketing, technology and marketing, psychology and tourism impacts. $\mathrm{He}$ teaches subjects in the area of Digital and Social media Marketing, Marketing Strategy, and BusinessConsulting and Strategy. His work has been published in leading academic journals including International Journal of Information Management, Industrial Marketing Management,Psychology \& Marketing, Journal of Business Research, Journal of Consumer Behaviour, and Computers in Human Behaviour.

Yogesh K. Dwivedi is a Professor of Digital Marketing and Innovation and Founding Director of the Emerging Markets Research Centre (EMaRC) at the School of Management, Swansea University, Wales,UK. In addition, he holds a Distinguished Research Professorship at the Symbiosis Institute of Business Management (SIBM), Pune, India. Professor Dwivedi is also currently leading the International Journal of Information Management as its Editor-in-Chief. His research interests are at the interface of Information Systems (IS) and Marketing, focusing on issues related to consumer adoption and diffusion of emerging digital innovations, digital government, and digital and social media marketing particularly in the context of emerging markets. Professor Dwivedi has published more than 300 articles in a range of leading academic journals and conferences that are widely cited (more than 29 thousand times as per Google Scholar). He was recently named on the annual Highly Cited Researchers ${ }^{\mathrm{TM}} 2020$ list from Clarivate 
Analytics. Professor Dwivedi is an Associate Editor of the Journal of Business Research, European Journal of Marketing, Government Information Quarterly and International Journal of Electronic Government Research, and Senior Editor of the Journal of Electronic Commerce Research. More information about Professor Dwivedi can be found at: http://www.swansea.ac.uk/staff/som/academic-staff/y.k.dwivedi/

Dr Laurie Hughes is a lecturer within the Strategic Operations group and an active member of the new Digital Futures research centre at the School of Management, Swansea University, Wales, UK. He has extensive management experience in a variety of roles working within industry on numerous projects in finance, manufacturing, operations, and business transformation within public, private and secure government organisations prior to his role in academia. Laurie has a $\mathrm{PhD}$ in Information Systems, an M.Sc. in Computer Science and a BEng in Computer Systems Engineering. He has taught a range of technology focussed topics at undergraduate and postgraduate levels up to MBA.
Laurie has published across a range of technology focussed research topics within leading academic journals in subjects such as: Artificial Intelligence, Blockchain, Industry 4.0, IS project failure, Supply Chain Management and Digital Marketing, that have been widely cited within the academic literature. He is a reviewer for the: International Journal of Information Management; Annals of Operations Research, Government International Quarterly and Production and Planning Control.

Frederic Boy is an Associate Professor of Management and Psychology in Swansea University's School of Management and an honorary Senior Lecturer at University College, London. His research interests include cognitive psychology, artificial intelligence and innovation. $\mathrm{He}$ has worked on a range of multidisciplinary projects in academic, industrial and clinical contexts, with a recent focus on the interplay between AI and psychological wellbeing. Working with a range of international and local partners, his work has led to the founding of spin-out companies based on disruptive technologies. 